\title{
Characterization of an umbilical cord blood sourced product suitable for allogeneic applications
}

\author{
Mukta S Sane ${ }^{\ddagger 1}$, Huiyuan Tang ${ }^{\ddagger 1}$, Neha Misra ${ }^{1}$, Xinzhu Pu²，Sara Malara ${ }^{1}$, Christopher D \\ Jones $^{*, 1}$ \& Soumyajit Banerjee Mustafi $* *, 1$ \\ ${ }^{1}$ Department of Research \& Development, Burst Biologics, Boise, ID 83705, USA \\ ${ }^{2}$ Biomolecular Research Center, Boise State University, Boise, ID 83725, USA \\ *Author for correspondence: Tel.: +1 888322 1191; Fax: +1 208629 5866; cjones@smart-surgical.com \\ **Author for correspondence: Tel.: +1 888322 1191; Fax: +1 208629 5866; sbanerjee@smart-surgical.com \\ $\ddagger$ Authors contributed equally
}

\begin{abstract}
Aim: Umbilical cord blood (UCB) sourced allografts are promising interventions for tissue regeneration. As applications of these allografts and regulations governing them continue to evolve, we were prompted to identify parameters determining their quality, safety and regenerative potential. Materials \& methods: Flow-cytometry, mass-spectrometry, protein multiplexing, nanoparticle tracking analysis and standard biological techniques were employed. Results: Quality attributes of a uniquely processed UCB-allograft (UCBr) were enumerated based on identity (cell viability, immunophenotyping, proteomic profiling, and quantification of relevant cytokines); safety (bioburden and microbiological screening), purity (endotoxin levels) and potency (effect of UCBr on chondrocytes and mesenchymal stem cells derived exosomes). These attributes were stable up to 24 months in cryopreserved UCBr. Conclusion: We identified a comprehensive panel of tests to establish the clinical efficacy and quality control attributes of a UCB-sourced allograft.
\end{abstract}

First draft submitted: 6 May 2019; Accepted for publication: 28 June 2019; Published online: 17 July 2019

Keywords: endotoxin $\bullet$ exosomes $\bullet$ graft versus host disease $\bullet$ quality control $\bullet$ tissue regeneration

The field of regenerative medicine holds abundant promise for the treatment of diseases afflicting millions worldwide. Thousands of clinical trials are underway for trauma and degenerative conditions in the USA alone (www.clinicaltrials.gov). The interest in the field is further amplified by the aging population's need to find alternatives to surgery, effectively offloading the financial burden from the healthcare system as well as patients [1]. An in-depth understanding of stem cell biology and therapeutic benefits of cytokines, along with improved techniques for optimizing these factors are helping regenerative medicine to grow at an unprecedented pace.

Recent research has demonstrated that UCB is a convenient source of adult stem cells containing hematopoietic (HSC) as well as mesenchymal stem cells (MSC) [2,3]. HSC in cord blood prompted its application in certain hematological diseases [4], whereas the presence of multipotent MSC that can differentiate into other structural tissues like bone and cartilage has further expanded the potential applications of UCB [5-7]. While the cellular characteristics of UCB have been extensively studied for the purposes of clinical applications, not enough has been reported on regenerative potential of the associated biomolecules. This is partly because regenerative medicine has long been associated with stem cell therapy. However, it has been shown that regenerative potential is often derived from the paracrine effect of the interventions and the activated host stem cells, rather than the direct involvement of exogenous cells administered at the site of injury [8]. We have previously demonstrated that a uniquely processed UCB product contains cytokines and growth factors, which are integral to bone regeneration [9]. These factors initiate signaling crosstalk with target cells that positively impacts the molecular milieu of the tissue microenvironment [10].

Exosomes are extracellular vesicles (EVs) comprising of several factors including cytokines. MSC release EVs packed with proteins and genomic materials which induce biological changes in the target cells to accomplish tissue regeneration [11]. Translational research on exosomes derived from the MSC have demonstrated that they can mimic the therapeutic attributes of the MSC themselves [12-14]. Clinical trials on rheumatic pathologies, cartilage 
development, brain injury and cardiovascular diseases are also currently testing this hypothesis [15]. Based on these findings, clinical suitability of cord blood allografts must account for the noncellular components while evaluating its promising role in tissue regeneration.

As UCB allografts are increasingly used in the clinics for tissue regeneration, the regulatory framework continues to evolve. Such products may be classified and regulated differently from cell and gene-based therapies. The quality control guidelines for cyto/genetic therapy includes cell identity, viability, purity, sterility and potency to minimize lot-to-lot variability [16]. Since UCB allografts are a complex embodiment of cellular and noncellular components, a quality control approach recommended for such products should be appropriately modified to address suitability and release criteria. Claims to regenerative function of these allografts should be based on characterization of identity and consistency of the noncellular components. UCB allografts have heterogeneous cellular and molecular composition due to inherent donor variability and alterations in the processing methodologies will add to this factor [17]. Variability can however be largely reduced, if not completely eliminated, by careful optimization of the manufacturing process and ensuring a stringent quality control mechanism.

The present study is aimed to address the unmet need for a uniform quality control framework to determine clinical suitability and safety of cord blood allografts. A uniquely processed UCB sourced allograft (UCBr) reportedly used for soft tissue and ligament repair application was investigated for identity, purity, safety and stability. Additionally, it is important to determine the biological potency of $\mathrm{UCBr}$ to establish a comprehensive quality control regime. The potency assays provide the mechanistic insight into how noncellular components of $\mathrm{UCBr}$ support biological processes, which may positively impact cartilage repair. Finally, the long-term stability of UCBr was over a period of 24 months. Taken together, to the best of our knowledge, this is the first study that identifies a comprehensive panel of tests to adequately address the quality attributes, clinical suitability and efficacy of UCB-sourced allografts.

\section{Materials \& methods \\ UCB-sourced allograft}

UCB obtained from consenting donors was processed by the patent pending method following US FDA's regulatory guidelines. UCB-sourced allografts, UCBr (BioBurst Rejuv, Burst Biologics, ID, USA) were stored at $-80^{\circ} \mathrm{C}$ until further use.

\section{Preparation of UCBr lysate}

$\mathrm{UCBr}$ was sonicated on ice (three pulses of $10 \mathrm{~s}$ each), centrifuged at $12,000 \mathrm{~g}$ for $15 \mathrm{~min}$ at $4^{\circ} \mathrm{C}$ and supernatant was collected and used for downstream experiments. Supernatant was not subjected to more than one freeze thaw cycle. When appropriate, supernatant was diluted in serum free media (SFM) at 1:5 or 1:10 dilution.

\section{Cells \& tissue culture media}

Human Knee Articular Chondrocytes (HC, Lonza CC-2550) were cultured in the basal media supplemented with growth kit (cell applications; 410PR-500 and 411-GS). Bone marrow derived mesenchymal stem cells (MSC, ATCC, PCS-500-012) were also cultured in the respective basal media supplemented with growth kit (ATCC; PCS-500-030 and PCS-500-041). Cells were maintained in a humidified incubator at $37^{\circ} \mathrm{C}$ with $5 \% \mathrm{CO}_{2}$. Cells between passages 3 and 5 were used for all experiments.

\section{Cell viability measurement}

$\mathrm{UCBr}$ was passively thawed and mixed in equal volumes with acridine orange/propidium iodide (AO/PI) staining solution. The mixture was loaded onto the SD100 cell counting chamber slides, and cells were visualized and counted using Cellometer K2 (Nexcelom, MA, USA). Data were analyzed using the K2 software optimized for frozen peripheral blood mononuclear cells (PBMC) using 15-micron cutoff for nonviable cells.

\section{Fluorescence activated cell sorting}

$\mathrm{UCBr}$ was thawed and added dropwise into RPMI supplemented with 10\% FBS and 400 units of DNAse. The cell suspension was centrifuged at $300 \mathrm{~g}$ for $5 \mathrm{~min}$, and the cell pellet was resuspended in 10\% FBS/RPMI containing 50 units of DNAse. Cells were sequentially washed with PBS and FACS Buffer (2\% FBS/HBSS, 2 mM EDTA). Cells were stained with antibodies (listed in Supplementary Material). Cells stained with all the fluorophores minus one fluorophore (FMO) were used as controls to determine the gating boundaries of positive and negative 
populations. Unstained and single-stained beads were used to calculate compensation values using the automated calculation function. Flow cytometry was performed on an ACEA NovoCyte with blue and red lasers and detectors for six color analysis. 10,000 events at $14 \mathrm{ml} / \mathrm{min}$ were collected for compensation controls and 100,000 events at $35 \mathrm{ml} / \mathrm{min}$ were collected for UCBr cells.

\section{Mass spectrophotometry \& proteomic analysis}

LC-MS/MS was performed using methods established previously with modifications [18]. Briefly, UCBr lysates were run for approximately $1 \mathrm{~cm}$ in $10 \%$ Bis-Tris gel and excised gel pieces were reduced, alkylated and digested with trypsin overnight at $37^{\circ} \mathrm{C}$ (Thermo Fisher Scientific, MA, USA). LC-MS/MS analysis of the resulting tryptic peptides was conducted on a Velos Pro Dual-Pressure Linear Ion Trap mass spectrometer equipped with a nano electrospray ionization source and coupled with an Easy-nLC II nano LC system (Thermo Fisher Scientific). Raw spectrum data were searched against the UniProtKB/Swiss-Prot protein database for Humans (acquired from www.uniprot.org on 12 February 2019). Further analysis was done using Database for Annotation, Visualization and Integrated Discovery web tool to analyze candidate genes and pathways [19].

\section{Cytokine measurement}

Cytokine concentration was measured in UCBr lysate (prepared from 31-64 donors) using multiplex ProcartaPlex Panel (Invitrogen, EPX450-12171-901). Luminex xMAP magnetic-bead fluorescent immunoassays (Invitrogen) were run on MAGPIX ${ }^{T M}$ and measurements were done as per the manufacturer's protocol. Universal assay buffer provided baseline values for the assay. For each standard, percent recovery values outside $90-110 \%$ were invalidated using xPonent Analysis software and concentration of cytokines were calculated using a standard curve with $\mathrm{R}^{2} \geq 0.9$.

\section{Maternal peripheral blood serology \& UCB bioburden testing}

Maternal peripheral blood samples were tested for infectious diseases using antibody-based, nucleic acid based and PCR-based detection methods. Serology testing was performed at VRL (TX, USA), a Clinical Laboratory Improvement Amendments certified laboratory. UCB samples were tested for anerobic and aerobic bacterial contamination prior to processing as per current Good Tissue Practice (cGTP) guidelines. To test possible contamination of UCBr, it was passively thawed and inoculated in either TSB, Sabdex or FTH broth and corresponding agar plates. For all tests appropriate positive and negative controls were included. Growth was monitored every 72 h up to 14 days.

\section{Endotoxin test}

Endotoxin levels were determined in UCBr directly using EndoSafe ${ }^{\circledR}$ nexgen PTS $^{\top \mathrm{T}}$ and US FDA licensed cartridges (PTS2005F or PTS5505F, sensitivity - 0.05 EU/ml, Charles River, MA, USA) following manufacture's protocol.

\section{Mixed lymphocyte reaction}

PBMCs were isolated from the buffy coat of healthy donors (PBMC Donor \#36, male, age 46 years, White; Donor \#50, male, age 25 years, White; Donor \#42, female, age 24years, African American) by Ficoll density gradient centrifugation and cryopreserved. Prior to use, the cryopreserved samples were thawed and rested at $37^{\circ} \mathrm{C}$ overnight in RPMI-1640 medium supplemented with 10\% fetal bovine serum. Cryopreserved UCBr were thawed and plated at $10^{5}$ cells/well in a 96-well plate. Rested PBMC cells were co-cultured with $1 \times 10^{5} \mathrm{UCBr}$ cells or PBMCs from unrelated donor at a density of $2 \times 10^{5}$ cells/well in the mixture of $200 \mu$ AIM-V. For mitogenic stimulation, the PBMC cells were stimulated with $2 \mu \mathrm{g} /$ well phytohemagglutinin. Background controls were performed for all $\mathrm{UCBr}$ samples and each institutional review board donor. Cells were incubated at $37^{\circ} \mathrm{C}$, in a $5 \% \mathrm{CO}_{2}$ incubator for 4 days. Bromo-deoxy uridine (BrdU) was added on day 3, and proliferative responses were determined by absorbance based BrdU ELISA assay on day 4 (Roche, Basel, Switzerland). BrdU optical density was recorded at $450 \mathrm{~nm}$. The assay was performed by Xeno Diagnostics, LLC (IN, USA) and PBMC used were approved through their institutional review board program.

\section{Cell proliferation}

$\mathrm{HC}$ and MSC were seeded at density of 5000 cells/well in a 96-well plate and incubated overnight. Cells were starved for $2 \mathrm{~h}$ and then grown in SFM, complete media or diluted UCBr lysates (1:10 or 1:5) for additional 
24 h. Cell proliferation was measured by CyQUANT (Thermo Fisher Scientific) assay according to manufacturer's protocol.

\section{Transwell cell migration}

Transwell inserts were coated with $5 \mu \mathrm{g} / \mathrm{ml}$ of fibronectin (Sigma-Aldrich, MO, USA) and left overnight for surface adsorption. HC were serum-starved for $2 \mathrm{~h}$, suspended in SFM and $4 \times 10^{4}$ cells were added to the upper chamber of a 24 -well, $8 \mu \mathrm{m}$ pore membrane transwell insert. Complete media, SFM or UCBr lysate (1:10) were added to the lower chamber as a chemoattractant. After $24 \mathrm{~h}$, cells on the upper surface were removed, cells on the lower surface were fixed in 5\% glutaraldehyde (Sigma-Aldrich, MO, USA), stained with $1 \%(\mathrm{w} / \mathrm{v})$ crystal violet (Sigma-Aldrich) and visualized at $20 \times$ magnification under stereoscope (Leica, NJ, USA).

\section{RNA isolation \& reverse transcriptase PCR}

Cells were treated with UCBr lysates (1:5) for 18-20 h, total RNA was extracted using Quick RNA kit (Zymo Research, CA, USA) and $1 \mu \mathrm{g}$ was reverse transcribed into cDNA and subsequently amplified with appropriate primers (listed in Supplementary Material) using SuperScript ${ }^{T M}$ VILO $^{T M}$ cDNA Synthesis Kit and Power SYBR ${ }^{T M}$ Green PCR Master Mix (Thermo Fisher Scientific) respectively. All reactions were run in QuantStudio 3 (Thermo Fisher Scientific), and data are represented as relative mRNA expression with $18 \mathrm{~s}$ rRNA as internal control.

\section{Western blot analysis}

Proteins were extracted in RIPA buffer (Thermo Fisher Scientific) from cells treated with UCBr lysates (1:5) for $24 \mathrm{~h}$ and estimated by BCA assay. Total $20-60 \mu \mathrm{g}$ of proteins were separated in 10\% Bis-Tris gels by electrophoresis, transferred onto nitrocellulose membrane and immunoprobed with antibodies to detect HMOX1, Cu/ZnSOD, MnSOD, Catalase, Thioredoxin 1 (Cell Signaling Technologies, MA, USA) and Hsp60 (SCBT, TX, USA). Chemiluminescence was captured with iBright FL1000 (Thermo Fisher Scientific). Hsp60 was used as loading control and was used for normalization of band intensities using ImageJ software.

\section{Exosome isolation \& characterization}

MSC in $100 \mathrm{~mm}$ culture plates with $80-90 \%$ confluency were briefly subjected to $2 \mathrm{~h}$ of serum starvation. Cells were subsequently treated with UCBr lysate (pooled from 6 or more donors) for $18 \mathrm{~h}$. Exosomes were extracted by Total Exosome Isolation (TEI) kit according to manufacturer's protocol (Thermo Fisher Scientific) or Exo-Quick kit (SBI, CA, USA). Isolated exosomes were first characterized by fluorescent nanoparticle tracking analysis (performed by System Biosciences, CA, USA). For downstream proliferation assay on HC and MSC, cells were treated with isolated exosomes diluted 1:2 for $24 \mathrm{~h}$. Cytokine level was measured as described previously. All experiments, including the exosome analysis, were repeated twice independently, each time at least in triplicates.

\section{Data analysis \& statistics}

All experiments, unless otherwise stated, were repeated independently three-times. All cell biological assays were performed with UCBr lysates obtained from at least three donors. Data are expressed as mean \pm standard deviation or standard error of the mean as indicated. Student's t-test and ANOVA were used for statistical analysis between two groups, and among three or more groups respectively. Statistical significance was set at $\mathrm{p}<0.05\left(^{*}\right)$.

\section{Results}

Characterization of the cellular components of $\mathrm{UCBr}$

Our previous publication shows that intact cells in a cord blood allograft are not directly involved in the regeneration process, and possibly act as reservoirs of the intracellular and membrane bound cytokines that are released by autolysis or passive secretion. We specifically demonstrated that the cytokine concentration in the conditioned media (CM) derived from intact UCB allografts was not significantly different from the CM derived from lysed UCB allografts [9]. However, it is critical that we evaluate the cellular components in UCBr from a quality control perspective, as the reproducibility of cell viability and characteristics will indicate a consistent processing technique.

\section{Cell viability assay}

Total 21 random lots of $\mathrm{UCBr}$, stored at $-80^{\circ} \mathrm{C}$ for a period of at least 30 days post processing were passively thawed and viability of the primary cell population was measured. Cell count, viability and diameter were determined by 


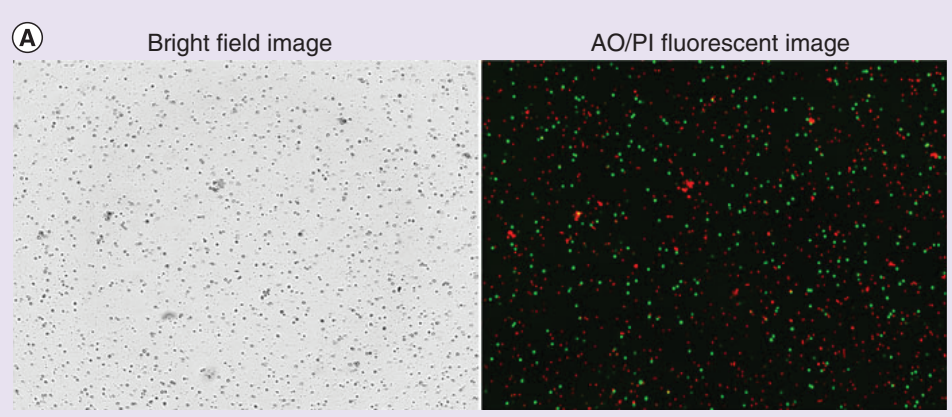

(B)

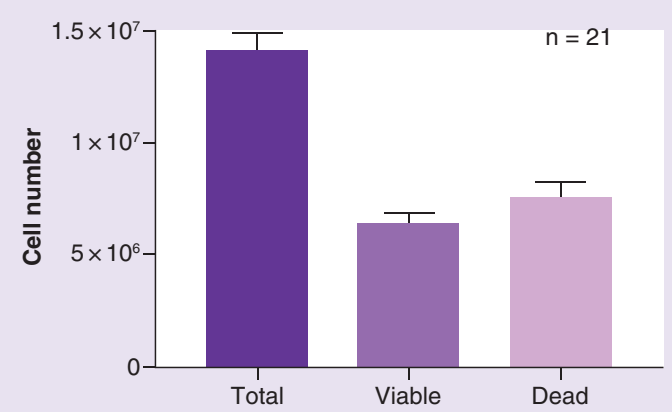

(C)

(D)

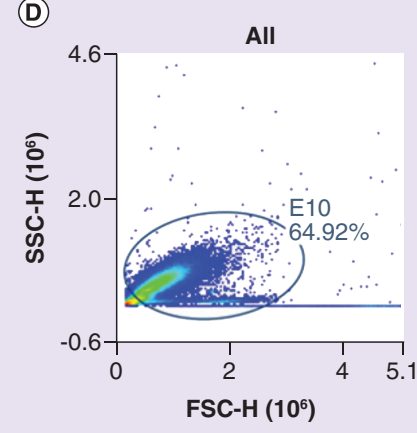

(G)

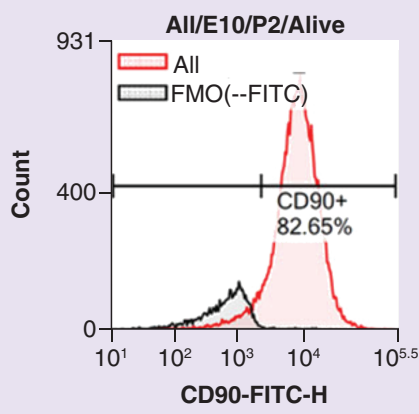

(E)

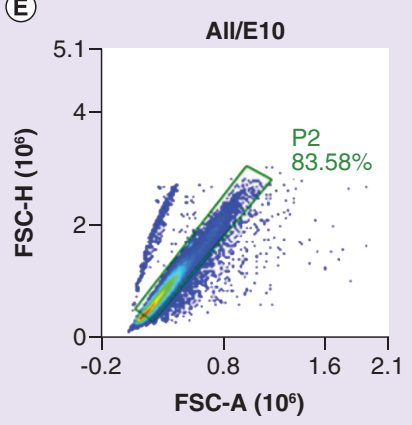

(H)

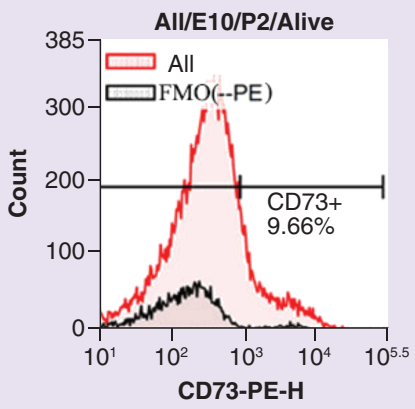

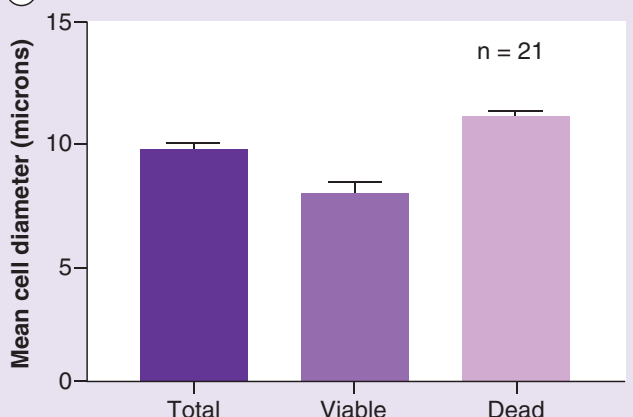

(F)

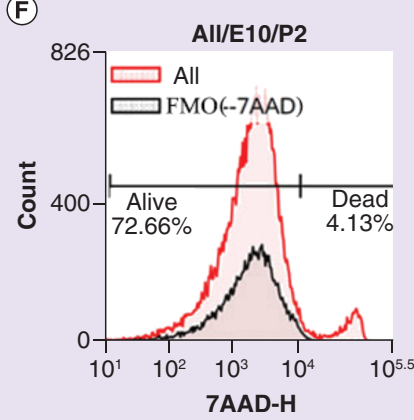

(I)

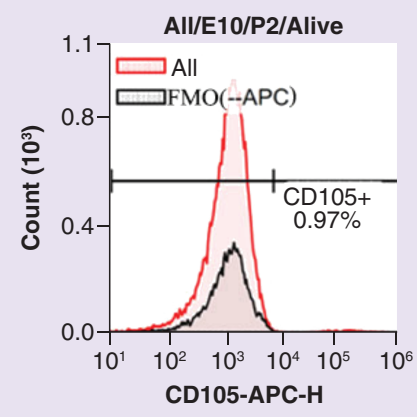

Figure 1. Characterization of cellular components of umbilical cord blood allograft by cell viability measurement and immunophenotyping using flow cytometry. UCBr from 21 donors was passively thawed and mixed with AO/PI dye solution and visualized under Nexcelom K2. (A) Representative photomicrographs of a random field with bright field (left panel) and fluorescence (right panel) were shown, AO-green/viable and PI-red/dead. (B) Cell number and (C) cell diameter were quantified. Values are expressed as mean \pm standard deviation. (D-N) Expression of surface markers of UCBr cells from a representative donor. Cells were appropriately gated (D, E \& K). In figures (F-J), 'all' indicates cells stained with CD90-FITC, CD73-PE, CD105-APC, CD45-PerCp-Cy5.5 and 7-AAD monoclonal antibodies and 'fluorophore' indicates cells stained with all the fluorophores minus the one as labeled in respective figures. Viability determined by 7-AAD exclusion (L) and stained with CD34 and CD45 monoclonal antibodies to determine CD34+ and CD45 ${ }^{+}$cells (M \& N). (O) The average expression percentage of cells stained with individual or combination of antibodies in $\mathrm{UCBr}$. AO: Acridine orange; PI: Propidium iodide; UCBr: Umbilical cord blood allograft. 
(J)

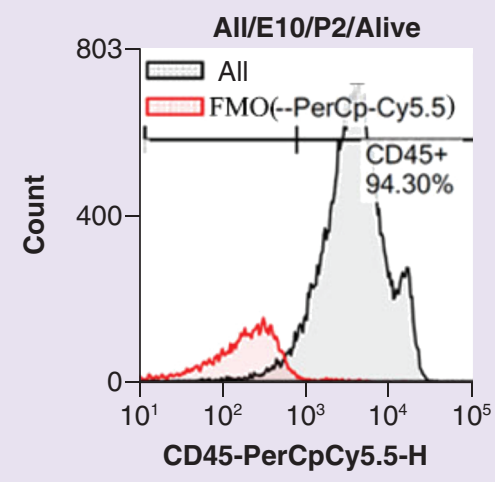

(1M)

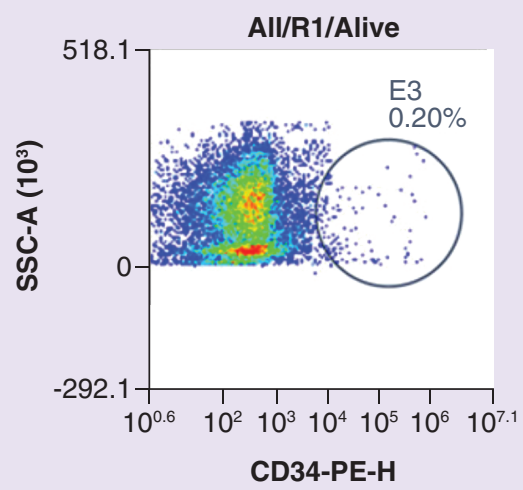

(K)

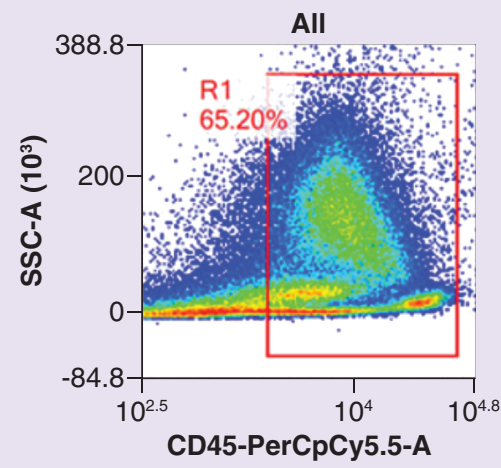

(N)

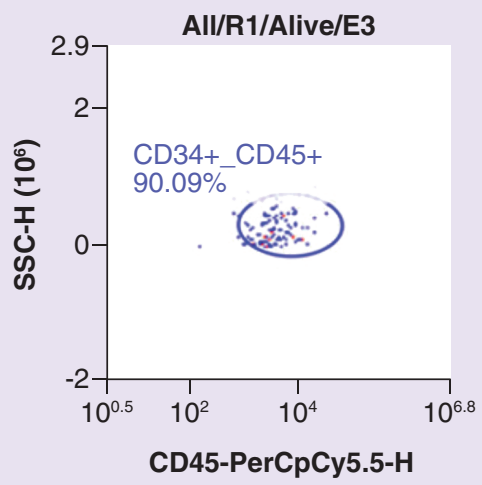

(L)

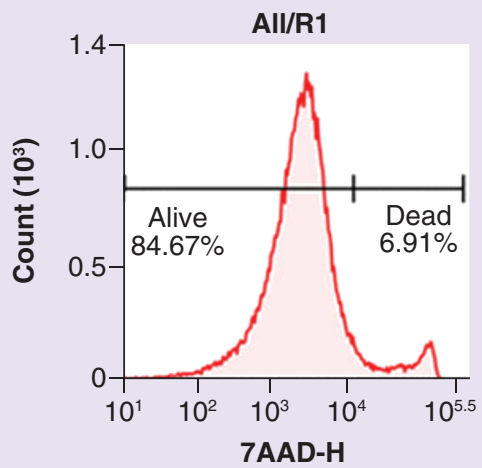

(0)

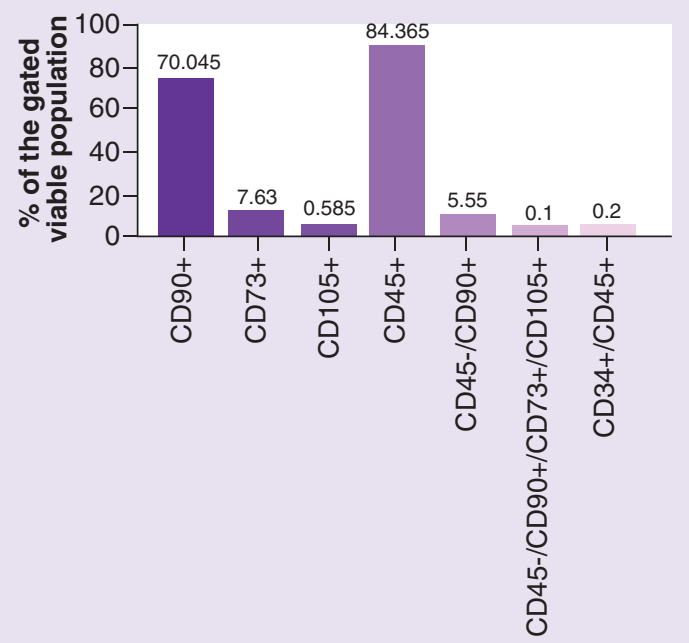

Figure 1. Characterization of cellular components of umbilical cord blood allograft by cell viability measurement and immunophenotyping using flow cytometry (cont.). UCBr from 21 donors was passively thawed and mixed with $\mathrm{AO} / \mathrm{PI}$ dye solution and visualized under Nexcelom K2. (A) Representative photomicrographs of a random field with bright field (left panel) and fluorescence (right panel) were shown, AO-green/viable and PI-red/dead. (B) Cell number and (C) cell diameter were quantified. Values are expressed as mean \pm standard deviation. (D-N) Expression of surface markers of UCBr cells from a representative donor. Cells were appropriately gated (D, E \& K). In figures (F-J), 'all' indicates cells stained with CD90-FITC, CD73-PE, CD105-APC, CD45-PerCp-Cy5.5 and 7-AAD monoclonal antibodies and 'fluorophore' indicates cells stained with all the fluorophores minus the one as labeled in respective figures. Viability determined by 7-AAD exclusion (L) and stained with CD34 and CD45 monoclonal antibodies to determine $\mathrm{CD}^{+} 4^{+}$and $\mathrm{CD} 45^{+}$cells (M \& N). (O) The average expression percentage of cells stained with individual or combination of antibodies in UCBr. AO: Acridine orange; PI: Propidium iodide; UCBr: Umbilical cord blood allograft.

bright field and dual-fluorescence imaging using acridine orange/propidium iodide staining (Figure 1A). The mean total cell count was $14.1 \pm 3.4$ million and the viability was close to $50 \%$. The mean diameter was $8 \pm 1.4 \mu \mathrm{m}$ for viable and $11.12 \pm 0.85 \mu \mathrm{m}$ for the nonviable cells (Figure 1B \& C).

\section{Characterization of UCBr cells by flow cytometry}

All studies reporting isolation of MSC from UCB have allowed the cord blood cells to adhere to culture dishes and expand for a few generations before performing flow-cytometry to characterize MSC based on cell surface markers [20-22]. Other methods like fluorescence activated cell sorting (FACS) have been used to enrich and purify the small but significant fraction of stem cells present in UCB [23]. Without such downstream manipulations, the sensitivity of the current assay procedures makes it extremely difficult to identify the stem cell population 
directly in the UCB cells [24]. Therefore, instead of identifying a particular subpopulation of cells in UCBr through lineage specific enrichment, we chose to characterize the heterogeneous population by immunophenotyping. Two $\mathrm{UCBr}$ samples were thawed, washed and stained with respective antibodies. Dead cells were identified using 7Aminoactinomycin D (7AAD). Of the viable cells in $\mathrm{UCBr}$, the average expression of CD90, CD73, CD105, CD45 were $70.04 \pm 17.8 \%, 7.63 \pm 2.87 \%, 0.585 \pm 0.54 \%, 84.37 \pm 14.1 \%$ respectively, indicating a major population of the cells is lymphocytes (Figure 1D-O). CD45 cells that stained positive for CD90 were $5.55 \pm 0.48 \%$. As expected in such heterogeneous population of frozen UCB cells, less than $1 \%$ of the cells in $\mathrm{UCBr}$ stained for all the MSC markers $\left(\mathrm{CD} 45^{-} / \mathrm{CD} 90^{+} / \mathrm{CD} 3^{+} / \mathrm{CD} 105^{+}\right)$. Albeit very low, expression of HSC progenitor marker CD34 was also detected.

\section{Characterization of the noncellular components of $\mathrm{UCBr}$ \\ Mass spectrometric analysis of $\mathrm{UCBr}$}

In addition to cytokines, signaling molecules such as protein kinases and redox enzymes also impact tissue regeneration. To identify such signaling proteins, we performed proteomic analysis of UCBr lysates by mass spectrometry. Only those proteins identified with two or more peptides, an expected $p$-value of $<0.05$ and a false discovery rate of $\leq 1 \%$ were reported. Proteomic analysis of two UCBr samples using Uniprot human protein database identified 1801 and 2335 proteins respectively, including serine threonine kinase, mitogen activated protein kinase, tyrosine kinases, cyclin dependent kinases and von Willebrand factor in addition to growth factors like PDGF, TGF $\beta 1$ and FGF2 (data not shown).

We identified 784 proteins that were common between the samples (Figure 2A). The high overlap of proteins between the donors suggests that the UCBr processing technique is consistent and the methods for protein identification are reliable. Bioinformatic analysis of the overlapping proteins using Database for Annotation, Visualization and Integrated Discovery 6.8 and gene ontology annotation indicated that proteins common between the donors were mainly involved in wound healing, cell proliferation and migration, cell cycle, redox metabolism, glucose metabolism and signaling pathways (Figure 2B). Pathways that yielded a Fishers exact p-value $<0.05$ and involved at least eight genes were reported. All the molecular functions and biological processes identified by this bioinformatic analysis are physiologically relevant and clearly established the role of the noncellular component of the $\mathrm{UCBr}$ in tissue regeneration.

\section{Cytokine profiling of $\mathrm{UCBr}$}

Mass spectrometry analysis identified several signaling molecules including PDGF and VEGF in UCBr that play a critical role in wound healing and tissue repair (data not shown). We have previously reported 44 different cytokines in the cord blood allograft derived CM [9]. In this study, we quantified the cytokines present in the $\mathrm{UCBr}$ lysates (Figure 2C). This enabled a better understanding of the molecular composition of the product with a direct clinical relevance. Total 31 cytokines including several growth factors (PDGF and EGF), neurotrophic factors (BDNF), angiogenic factors (VEGF) and interleukins (IL-1, IL-2, IL-5, IL-8, IL-10) were identified in samples prepared from 31-64 donors. The mean concentration of the cytokines ranged from $7.83 \pm 0.3 \mathrm{pg} / \mathrm{ml}$ (SCF) to $30933 \pm 1901.2 \mathrm{pg} / \mathrm{ml}$ (IL-1RA). IL-1RA is a major anti-inflammatory cytokine and several clinical trials with IL-1RA have reported pain reduction in patients following acute injury [25]. Presence of important cytokines like EGF $(323.16 \pm 19.02 \mathrm{pg} / \mathrm{ml})$; PDGF-BB $(3256.8 \pm 495.9 \mathrm{pg} / \mathrm{ml})$ and VEGF $(1600.1 \pm 91 \mathrm{pg} / \mathrm{ml})$ in UCBr may be the regulatory factors for inducing cell proliferation, migration and angiogenesis and hence, constitute an important criterion to determine product quality and donor suitability.

\section{Pre- and postprocessing microbiological safety testing on $\mathrm{UCBr}$}

Absence of microbial contamination in the product is critical from clinical safety perspective and must be an integral part of the quality control process. $\mathrm{UCBr}$ is manufactured under controlled, clean room conditions with minimal environmental exposure which must be subsequently verified by an array of safety testing to ensure the aseptic nature of the final allograft.

\section{Infectious disease testing on maternal peripheral blood samples}

To begin with, a well-defined inclusion-exclusion criterion based on personal lifestyle, medical history, etc. determined donor initial qualification. Serology testing was performed by Clinical Laboratory Improvement Amendment certified lab as per US FDA's guidelines for human cells, tissues, and cellular and tissue-based product (HCT/Ps). 
(A)

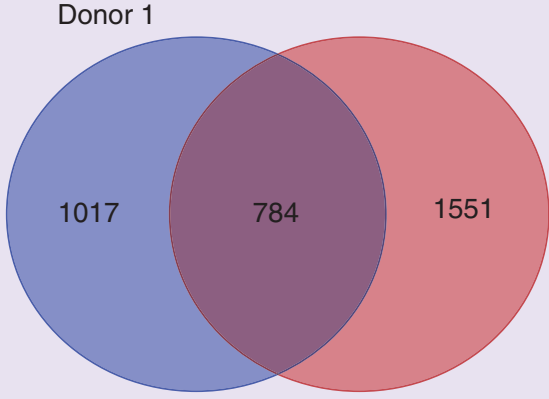

Donor 2

(B)

Carbohydrate metabolic process-

Gluconeogenesis

TNF-mediated signaling

MAPK cascade-

Integrin-mediated signaling pathway

Small GTPase-mediated signal transduction Wnt signaling pathway, planar cell polarity pathway

Positive regulation of ERK1 and ERK2 cascade

VEGF receptor signaling pathway

TGFb receptor signaling

NIK/NF-kB signaling

Oxidation-reduction process

Cell redox homeostasis

Response to reactive oxygen species

Cellular oxidant detoxification

Cell adhesion

Positive regulation of cell migration

Regulation of mRNA stability

Protein folding

Translation

G2/M transition of mitotic cell cycle

Cell proliferation

Osteoblast differentiation

Wound healing

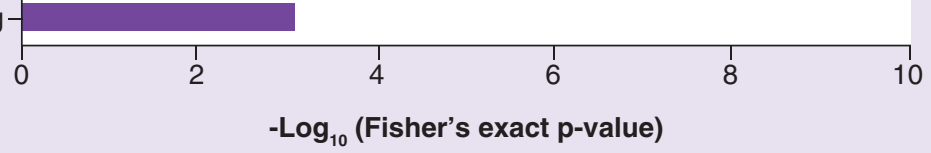

Figure 2. Characterization of noncellular components of umbilical cord blood allograft by mass spectrometry and protein multiplexing. (A) Venn diagram showing the number of unique and shared proteins in donor samples obtained by mass spectrometry. (B) Enrichment analysis of the 784 common proteins in donor samples using DAVID. (C) Protein multiplexing analysis for 31 cytokines in UCBr samples. Cytokine concentration was measured by Luminex XMAP technology on MAGPIX ${ }^{T M}$ platform and expressed as mean values in picograms/ml ( \pm standard error of the mean) from 31-64 donors.

UCBr: Umbilical cord blood allograft; DAVID: Database for Annotation, Visualization and Integrated Discovery. 
(C)

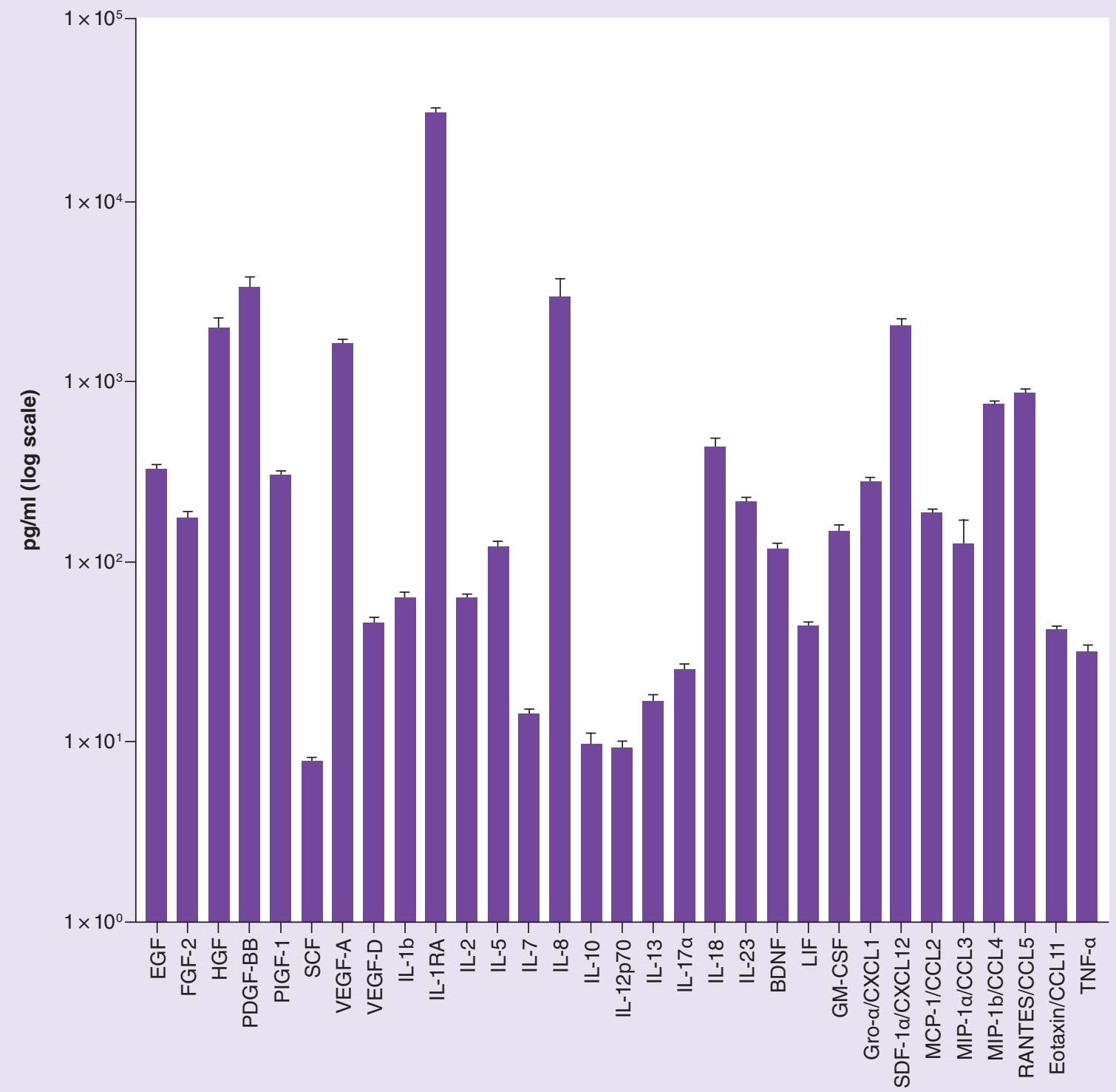

Figure 2. Characterization of noncellular components of umbilical cord blood allograft by mass spectrometry and protein multiplexing (cont.). (A) Venn diagram showing the number of unique and shared proteins in donor samples obtained by mass spectrometry. (B) Enrichment analysis of the 784 common proteins in donor samples using DAVID. (C) Protein multiplexing analysis for 31 cytokines in UCBr samples. Cytokine concentration was measured by Luminex XMAP technology on MAGPIX ${ }^{\top M}$ platform and expressed as mean values in picograms $/ \mathrm{ml}$ ( \pm standard error of the mean) from 31-64 donors.

UCBr: Umbilical cord blood allograft; DAVID: Database for Annotation, Visualization and Integrated Discovery.

Testing included detection of antibodies to HTLV-1 and 2, syphilis and hepatitis B surface antigen. Nucleic acid testing (NAT) was performed for hepatitis B, hepatitis C, HIV and West Nile virus. Peripheral blood samples were also tested for total antibody of CMV, while Zika and other flavivirus were identified by PCR amplification, to eliminate possibility of past or recent exposure to the virus because of traveling to certain geographical zones. In a typical 24 months period, $5.2 \%$ of the total donors were rejected due to positive antibody test, $1.2 \%$ were rejected due to positive NAT outcomes and $1.0 \%$ of the donors were rejected based upon PCR-based identification. Overall, 92.5\% donors were negative for any infectious disease serology and the cord blood collected from these donors underwent final processing (Table 1A). 
Table 1. Determination of product safety using pre- and postprocessing microbiological testing.

\begin{tabular}{|c|c|c|}
\hline \multicolumn{2}{|l|}{ Serology test } & Percentage positive \\
\hline \multicolumn{2}{|l|}{ Antibody-based detection } & 5.209 \\
\hline \multicolumn{2}{|l|}{ Nucleic acid test } & 1.195 \\
\hline \multicolumn{2}{|l|}{ PCR-based identification } & 1.0247 \\
\hline & & 7.42 (Total) \\
\hline \multicolumn{3}{|c|}{ (B) Umbilical cord blood microbial cultures } \\
\hline Incubation temperature & Culture media & Percentage positive \\
\hline $22.5^{\circ} \mathrm{C}$ & Tryptic soy broth & 0 \\
\hline \multirow[t]{3}{*}{$32.5^{\circ} \mathrm{C}$} & Fluid thioglycolate broth & 0.028 \\
\hline & Tryptic soy broth & 0.008 \\
\hline & & 0.036 (Total) \\
\hline \multicolumn{3}{|c|}{ (C) Umbilical cord blood product microbiological testing } \\
\hline Incubation temperature & Culture media & Percentage positive \\
\hline \multirow[t]{4}{*}{$22.5^{\circ} \mathrm{C}$} & Tryptic soy broth & 0 \\
\hline & Sabdex broth & 0.001 \\
\hline & Tryptic soy agar & 0 \\
\hline & Sabdex agar & 0 \\
\hline \multirow[t]{4}{*}{$32.5^{\circ} \mathrm{C}$} & Fluid thioglycolate broth & 0.007 \\
\hline & Tryptic soy broth & 0.006 \\
\hline & Tryptic soy agar & 0.007 \\
\hline & & 0.021 (Total) \\
\hline
\end{tabular}

(A) Percentage of maternal peripheral blood samples that tested positive for the presence of infectious serology using antibody, nucleic acid and PCR based testing in a period of 24 months. (B) Percentage of cord blood samples that tested positive in aerobic and/or anerobic microbial cultures over a period of 24 months. (C) Percentage of UCBr that were positive in either one or more growth-based microbiological culture tests in 24 months.

UCBr: Umbilical cord blood allograft.

\section{Microbial cultures on cord blood}

In order to determine if collection, storage and shipment of cord blood samples introduced any microbial contamination, it is important to test bioburden in cord blood. Each cord blood sample was tested for rapid growth of aerobic and anerobic organisms using tryptic-soy and fluid thioglycolate broth culture methods. In a period of 24 months, less than $0.04 \%$ of the total donors were rejected for positive bioburden outcomes (Table 1B).

\section{Quarantine \& microbiological quality control testing on final product post-thaw}

To ensure that none of the processing step(s) and/or reagent(s) introduced microbial contamination, one vial from each donor lot of the final UCBr product stored at $-80^{\circ} \mathrm{C}$ was thawed and tested. Broth and plate-based cultures were monitored every 3-5 days, up to 2 weeks. Temperature and growth media were suitable to determine presence of fungi and aerobic, anerobic as well as facultative bacteria. In a period of 24 months, approximately $0.02 \%$ of the total donor lots tested were found to be positive for one or more types of contamination and summarily discarded (Table 1C).

\section{Purity of $\mathrm{UCBr}$}

Endotoxin Assay

Presence of bacterial endotoxin, 'pyrogens' may induce fever and other adverse reactions caused by inflammatory mediators. Commercially available products marketed as HCT/Ps are regulated solely as section 361 of PHS Act and regulation 21 C.F.R 1271. Such products do not require endotoxin testing under cGTP. Nevertheless, reported use of such allografts often involves different routes of administration which may require information on the endotoxin levels. So, we identified criteria set forth under different regulatory frameworks while determining the allowable limit of endotoxin in UCBr. Therefore, endotoxin testing of $\mathrm{UCBr}$ is included in our quality control regimen. Current allowable limits for endotoxin range from $5 \mathrm{EU} / \mathrm{kg}$ bodyweight (non-IV drugs) to $0.2 \mathrm{EU} / \mathrm{kg}$ bodyweight (intrathecal application). Based on the most stringent criteria, we chose to qualify UCBr at the limit set for intrathecal applications. Considering a subject of $70 \mathrm{~kg}, 0.2 \mathrm{EU} / \mathrm{kg}$ limit allows up to $14 \mathrm{EU}$ in a single application. Endotoxin levels in $\mathrm{UCBr}$ were determined using a kinetic chromogenic test in which the reaction 
Table 2. Determination of product purity using endotoxin assay.

(A) Inhibition/enhancement test and detection of MVD

\begin{tabular}{|c|c|c|c|c|c|c|c|}
\hline \multicolumn{2}{|l|}{ Sample dilution } & S1 & S2 & S3 & S4 & S5 & S6 \\
\hline \multicolumn{2}{|l|}{$1: 10$} & $1298 \%$ & $80 \%$ & $139 \%$ & $81 \%$ & $166 \%$ & $186 \%$ \\
\hline \multicolumn{2}{|l|}{$1: 50$} & $98 \%$ & $81 \%$ & $81 \%$ & $125 \%$ & $110 \%$ & $122 \%$ \\
\hline \multicolumn{2}{|l|}{ 1:100 } & $89 \%$ & $76 \%$ & $98 \%$ & $130 \%$ & $94 \%$ & $127 \%$ \\
\hline \multicolumn{2}{|l|}{$1: 250$} & $76 \%$ & $72 \%$ & $125 \%$ & $115 \%$ & $145 \%$ & $106 \%$ \\
\hline \multicolumn{8}{|c|}{ (B) Endotoxin values of seven representative UCBr by kinetic chromogenic LAL test } \\
\hline $\mathrm{UCBr}$ & 1 & 2 & 3 & 4 & 5 & 6 & 7 \\
\hline Dilution & $1: 50$ & $1: 50$ & $1: 50$ & $1: 50$ & $1: 50$ & $1: 50$ & $1: 50$ \\
\hline \multirow{2}{*}{$\begin{array}{l}\text { Sample reaction } \\
\text { time CV }\end{array}$} & $0 \%$ & $0 \%$ & $0 \%$ & $0 \%$ & $0 \%$ & $0 \%$ & $0 \%$ \\
\hline & Pass & Pass & Pass & Pass & Pass & Pass & Pass \\
\hline $\begin{array}{l}\text { Spike value } \\
\text { (recovered) }\end{array}$ & $0.325 \mathrm{EU} / \mathrm{ml}$ & $0.570 \mathrm{EU} / \mathrm{ml}$ & $0.460 \mathrm{EU} / \mathrm{ml}$ & $0.376 \mathrm{EU} / \mathrm{ml}$ & $0.456 \mathrm{EU} / \mathrm{ml}$ & $0.786 \mathrm{EU} / \mathrm{ml}$ & $0.614 \mathrm{EU} / \mathrm{ml}$ \\
\hline \multirow{2}{*}{$\begin{array}{l}\text { Spike reaction } \\
\text { time CV }\end{array}$} & $2.4 \%$ & $1.8 \%$ & $13.1 \%$ & $4.5 \%$ & $0.5 \%$ & $5.4 \%$ & $6.1 \%$ \\
\hline & Pass & Pass & Pass & Pass & Pass & Pass & Pass \\
\hline \multirow[t]{2}{*}{ Spike recovery } & $54 \%$ & $95 \%$ & $77 \%$ & $63 \%$ & $76 \%$ & $131 \%$ & $102 \%$ \\
\hline & Pass & Pass & Pass & Pass & Pass & Pass & Pass \\
\hline Test suitability & Pass & Pass & Pass & Pass & Pass & Pass & Pass \\
\hline Sample value & $<2.5 \mathrm{EU} / \mathrm{ml}$ & $<2.5 \mathrm{EU} / \mathrm{ml}$ & $<2.5 \mathrm{EU} / \mathrm{ml}$ & $<2.5 \mathrm{EU} / \mathrm{ml}$ & $<2.5 \mathrm{EU} / \mathrm{ml}$ & $<2.5 \mathrm{EU} / \mathrm{ml}$ & $<2.5 \mathrm{EU} / \mathrm{ml}$ \\
\hline
\end{tabular}

(A) Percentage spike recovery for UCBr from six donors using inhibition/enhancement test cartridge. Each sample was tested at four different dilution levels (1:10, 1:50, 1:100 and 1:250) with 1:50 dilution showing the most consistent spike recovery across the samples. Dilution of 1:50 was designated as MVD and used in the endotoxin testing. (B) Endotoxin testing parameters (sample value, spike recovery, \% spike recovery and spike recovery time CV) reported for UCBr from seven random donors using EndoSafe-NexGen-PTS platform.

CV: Coefficient of variation; MVD: Maximum valid dilution; UCBr: Umbilical cord blood allograft.

time of the sample is compared with that of control standard endotoxins (CSE). We tested four dilutions of UCBr ranging from $1: 10$ to $1: 250$ (Table $2 \mathrm{~A}$ ) to determine a maximum valid dilution that will not interfere with the biochemical reaction. We concluded that dilution of 1:50 was noninterfering and consistently yielded a spike recovery within 50-200\%. The exdotoxin limit for allograft release was set at $<2.5 \mathrm{EU} / \mathrm{ml}$ based on sensitivity of the cartridge $(0.05 \mathrm{EU} / \mathrm{ml})$ and MVD. All UCBr samples tested were $<2.5 \mathrm{EU} / \mathrm{ml}$. Representative values of seven samples are provided in Table $2 \mathrm{~B}$.

\section{Presence of undesirable components}

UCB based allografts are often processed using reagents that may have proteins of nonhuman origin and could potentially end up as residues in final product. Our processing technique for UCBr does not involve any such reagents and thus contaminating molecules are not expected. In order to confirm this, the proteins identified in UCBr samples by mass spectrometry were cross-checked against the Repository of Adventitious Proteins database that identifies contaminating proteins from dust, physical contact or common laboratory reagents like bovine serum albumin. No such contaminants were detected in any of the UCBr samples tested (data not shown).

\section{Immunogenicity of $\mathrm{UCBr}$}

UCB sourced allografts for homologous use are considered non-immunogenic as UCB cells are MHC class I (MHCI) dull and negative for MHC class II (MHCII) [26]. However, as applications of such allografts continue to evolve there is a need for direct measurement of the immunogenicity of the allograft itself as a part of the quality control regimen. Immune responsiveness of each of the three allogeneic human PBMC donors was evaluated in a mixed lymphocyte reaction (MLR) format with $30 \mathrm{UCBr}$ donors. Proliferative response was determined using a BrdU ELISA assay on day 4 (Figure 3). Allogeneic PBMC proliferative responses to all UCBr were negligible, being equal to or below mean baseline PBMC proliferative responses with stimulatory index (SI) $<1.2$. In contrast, the mean two-way control PBMC allogeneic responses for the three donors had SI values between 3.2 and 28.5. In 4-day MLR reaction, all UCBr samples displayed negligible SI compared with the positive control indicating that these cells were not metabolically active. In summary, UCBr failed to stimulate human PBMCs and were nonimmunogenic. 


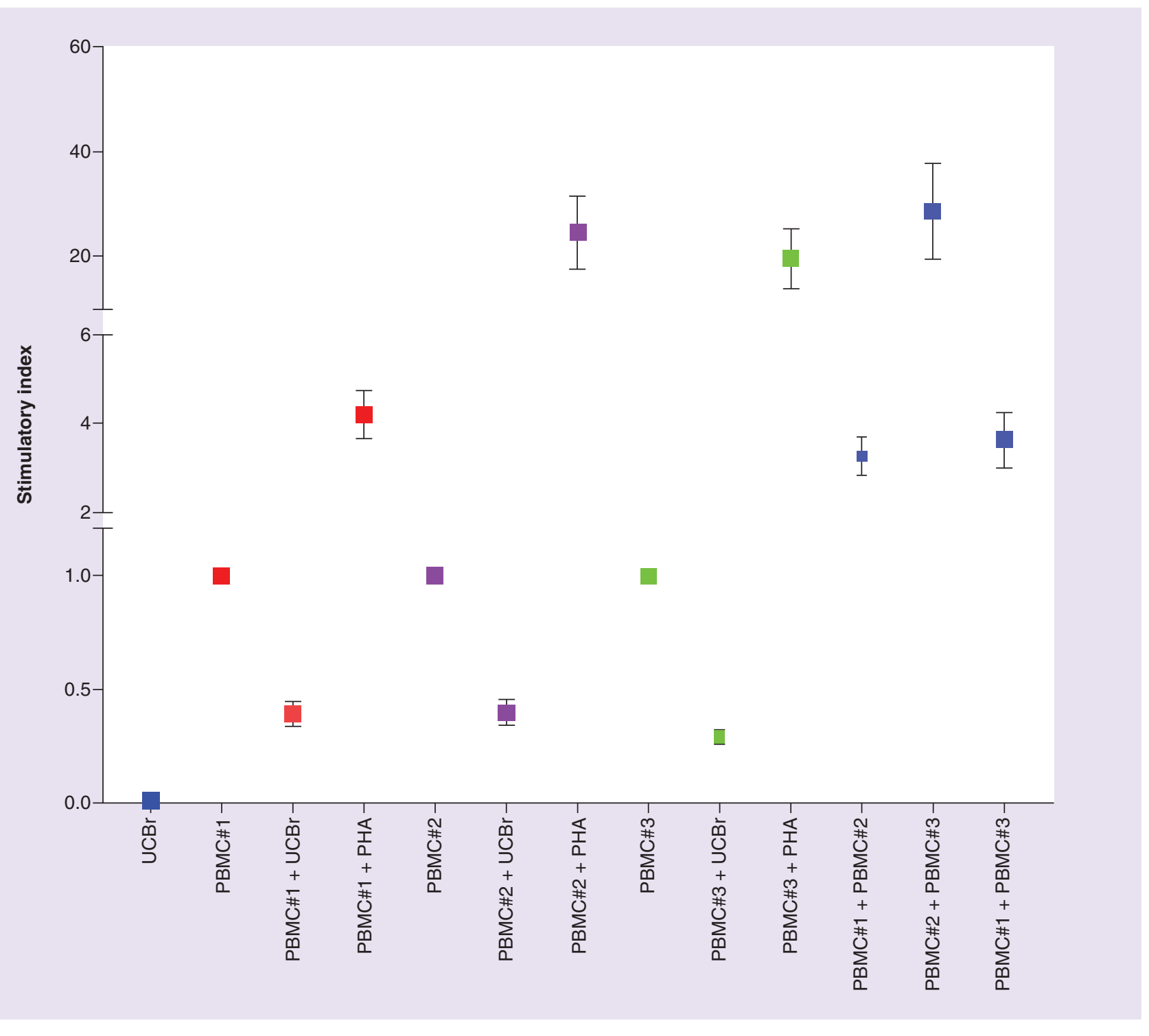

Figure 3. Immunological characterization of umbilical cord blood allograft in vitro. (A) Evaluation of UCBr immunogenicity in a two-way mixed lymphocyte reaction assay. Stimulatory index of 30 donors and three PBMCs is expressed as mean \pm standard deviation. Data were analyzed by Student's t-test and $p \leq 0.05$ was considered statistically significant. PBMC: Peripheral blood mononuclear cell; UCBr: Umbilical cord blood allograft.

\section{Determining the biological effects of $\mathrm{UCBr}$}

One of the reported applications of $\mathrm{UCBr}$ is for articular cartilage injuries. Articular cartilage has inherent limited healing potential, and its damage poses a challenging problem for orthopedic surgeons. The structure and function of this cartilage is dependent on the proliferation, migration and homeostasis of articular chondrocytes that are present in the cartilage. To determine potency, effects of $\mathrm{UCBr}$ were investigated on articular chondrocytes isolated from human knee.

\section{UCBr induces chondrocyte proliferation}

Articular chondrocytes proliferate and secrete extracellular matrix to maintain and sustain the cartilage, and constitutes a promising strategy for cartilage repair [27]. $\mathrm{UCBr}$ lysate at 1:10 and 1:5 dilution induced higher proliferation in $\mathrm{HC}$ after $24 \mathrm{~h}$ of treatment (Figure $4 \mathrm{~A}$ ) as compared with cells cultured in SFM with no other exogenous factors. $\mathrm{HC}$ treated with $\mathrm{UCBr}$ at 1:10 dilution showed approximately fourfold increase in proliferation, whereas 1:5 dilution showed about fivefold higher proliferation. Cells that were cultured in the complete growth 
(A)

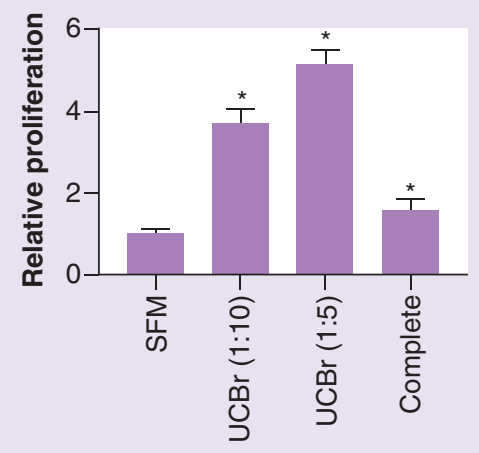

(B)

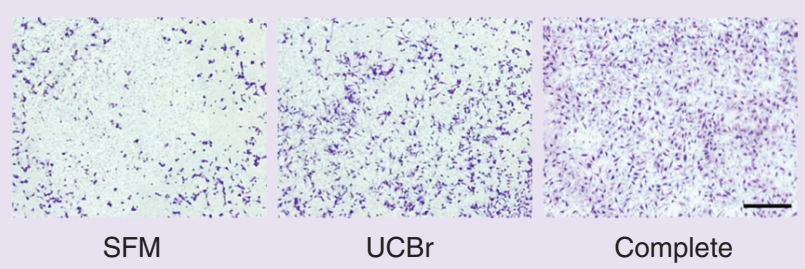

(c)

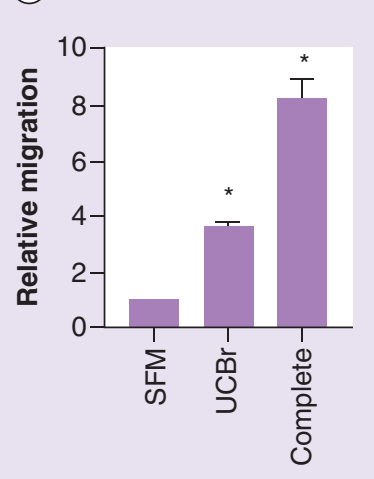

(D)

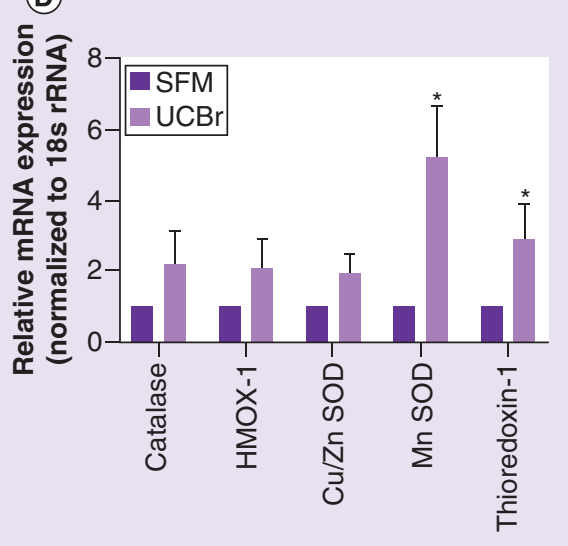

(E)

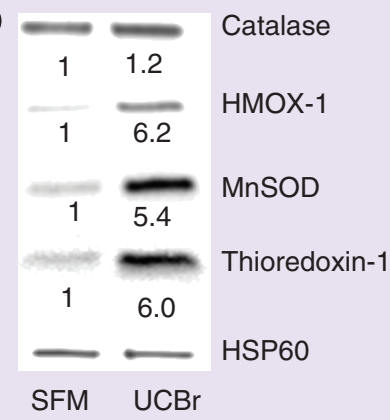

Figure 4. Biological effects of umbilical cord blood allograft. (A) Proliferation rate was measured by fluorescence quantification of total cellular DNA in HC treated with either SFM, UCBr lysates or complete media (10\% FBS) and data presented as mean \pm standard deviation relative to SFM treatment. (B) Cell migration of HC was evaluated using transwell system and representative photomicrographs of the migrated cells in response to SFM, UCBr lysates or complete media are provided. (C) Cells migrated per visual field were quantified using ImageJ, normalized first to SFM, then to the rate of proliferation and expressed as mean of relative migration \pm standard deviation. Experiments were repeated three-times, each time with 3-5 donors pooled together. (D) qPCR was performed on RNA extracted from HC treated with SFM or UCBr lysates pooled from at least three donors. The 18S rRNA transcript level was used to normalize the data, which are presented as mean values for fold change \pm standard deviation. (E) Protein levels of redox markers in $\mathrm{HC}$ treated as in (D) were determined by western blot. Densitometry was performed taking signals from Hsp60 as the internal control. Values are expressed relative to SFM treated control and indicated in the panels below the immunoblots. Data were analyzed by ANOVA and $p \leq 0.05$ was considered statistically significant. ${ }^{*} \mathrm{p} \leq$ 0.05; Scale bar: $50 \mu \mathrm{m}$.

FBS: Fetal bovine serum; HC: Human knee articular chondrocytes; Hsp60: Heat Shock Protein Family D; qPCR: Quantitative reverse transcription PCR; Redox: Reduction-oxidation; SFM: Serum-free media; UCBr: Umbilical cord blood allograft.

medium served as an internal reference of the normal cell proliferation rate. The proliferation rate of the UCBr treated cells was higher than the cells cultured in complete medium. Combination of cytokines and growth factors present in $\mathrm{UCBr}$ promotes chondrocyte proliferation.

\section{UCBr induces chondrocyte migration}

Chondrocyte migration is challenging as the cells need to overcome the density and pressure of the surrounding matrix to migrate to other sites. Research has shown that chondrocyte migration can help in restoring osteochondral defects [28]. The potential of the $\mathrm{UCBr}$ as a chemo-attractant was therefore specifically tested by transwell migration assay using complete growth medium (10\% FBS), SFM or UCBr lysates (1:10 dilution, Figure 4B). When normalized to their respective proliferation rate, the net migratory index of the $\mathrm{HC}$ cells treated with $\mathrm{UCBr}$ was 
$3.6 \pm 0.1(\mathrm{p}<0.05)$ fold higher when compared with that of the control cells (Figure 4C). These data indicate that the UCBr may aid in osteochondral repair by stimulating chondrocyte migration.

Impact of $U C B r$ on redox metabolism

There is ample evidence that cartilage degradation is often due to impaired ROS homeostasis. Strategies to target antioxidant systems may reduce degradation and aid in repair of damaged cartilage [29]. Bioinformatic analysis of the proteins identified in $\mathrm{UCBr}$ lysates by mass-spectrometry indicated that several of these proteins are involved in redox metabolism. Therefore, the effect of $\mathrm{UCBr}$ on antioxidant enzymes was evaluated both at the transcriptional and translational levels. mRNA expression of several redox marker genes was quantified in chondrocytes treated with UCBr lysates. MnSOD and Thioredoxin 1 were significantly bolstered by 5.2 -fold ( $\mathrm{p}<0.0001$ ) and 2.9-fold, respectively ( $\mathrm{p}<0.05$ ), when compared with untreated controls (Figure $4 \mathrm{D})$. Immunoblotting of these markers further confirmed that Thioredoxin 1 and MnSOD were also upregulated at the protein levels (Figure 4E) by similar treatment. Interestingly, mRNA level of $H M O X 1$ was not significantly upregulated at the transcriptional level but at the protein level HMOX1 expression increased ( $\sim 6.2$-fold) and was similar to Thioredoxin 1 ( $\sim 6.0$-fold) and MnSOD ( 5.4-fold). This might indicate a possible post-transcriptional modification of HMOX1 in HC. We were unable to detect $\mathrm{Cu} / \mathrm{ZnSOD}$ at appreciable levels by immunoblotting of control and treated HC.

\section{Determining the stability of $\mathrm{UCBr}$}

Based on literature, the current expiry period of $\mathrm{UCBr}$ was set at 24 months [30]. To establish that this criterion is valid, we compared certain aforesaid quality parameters between samples that were less than 24 months $(\mathrm{N}=26$, median of 3 months) and those above 24 months ( $N=23$, median 25 months). No significant difference in cell viability was observed between these groups (Figure $5 \mathrm{~A}$ ). As cytokines in $\mathrm{UCBr}$ are the key factors influencing tissue regeneration, concentration of seven cytokines (IL-8, IL-13, EGF, BDNF, FGF-2, PDGF-BB and VEGF-A) was measured in these two groups. compared with the samples grouped under $<24$ months, there was a slight but not statistically significant drop in the relative cytokine concentration (Figure 5B). The biological potency of the products was tested based on its effect on proliferation of HC. Proliferative rate of the samples less than 24 months and greater than 24 months were similar without any statistically significant difference (Figure 5C). Four additional samples between 24 and 30 months were tested for their aseptic nature and no growth was detected (Figure 5D). The endotoxin values of five representative samples between 24 and 30 months were also tested for their endotoxin limits and were found to be $<2.5 \mathrm{EU} / \mathrm{ml}$ (Figure 5E) same as the samples with median age of 3 months as shown in Table 2B.

\section{$\mathrm{UCBr}$ increases the yield of MSC derived exosomes}

Current dogma in regenerative medicine indicates that the EVs including exosomes released by the MSC have therapeutic benefits. Altering the conditions of culturing MSC have a significant influence not only on the yield but also on the efficacy of exosomes in terms of the proteomic and genomic complexities [14]. Here, we investigated if exosomes derived from MSC treated with UCBr lysates differ in yield and biological functions when compared with the ones derived from untreated MSC. EVs were characterized based on particle concentration and size distribution using fluorescence-based Nanoparticle Tracking Analysis which specifically identifies microparticles with intact membranes (Figure 6A \& B). The concentration of the EVs in the samples obtained from $\mathrm{UCBr}$ treated MSC was significantly higher ( $\sim$ twofold) compared with the untreated counterpart (Figure $6 \mathrm{C})$ ). Nano Tracking Analysis also confirmed a more homogeneous population of EVs obtained from untreated MSC (mean $104.4 \pm 20.7 \mathrm{~nm}$ ) compared with samples obtained from treated MSC which ranged from 91 to $698 \mathrm{~nm}$, with a mean of $288.7 \pm 4.1 \mathrm{~nm}$ (Figure 6A \& B). The heterogeneity of the particle size identified in samples derived from treated MSC may be attributed to the yield of a higher ratio of EVs of varying size in response to the $\mathrm{UCBr}$ treatment. The proliferative effect of these EVs was further tested on MSC and HC. EVs derived from UCBr lysate treated MSC showed approximately 2.1-fold (MSC) to approximately fivefold (HC) increase in proliferative rate when compared with the respective controls (Figure $6 \mathrm{D} \& \mathrm{E}$ ). Proteomic analysis of MSC-derived EVs has shown that they contain the factors influencing angiogenesis such as FGF, VEGF, HGF, EGF and IL-8 [13]. We measured the concentration of EGF and VEGF present in the exosomes derived from treated or nontreated MSC. In unit volume, EGF was approximately 2.14-fold higher and VEGF was approximately 2.8-fold higher in the exosomes released by the MSC pretreated with UCBr lysate (Figure 6C). 
(A)

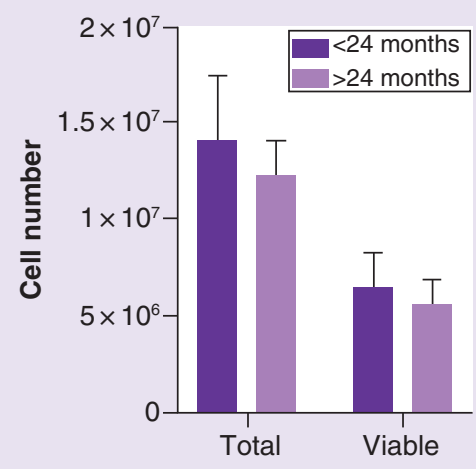

(B)

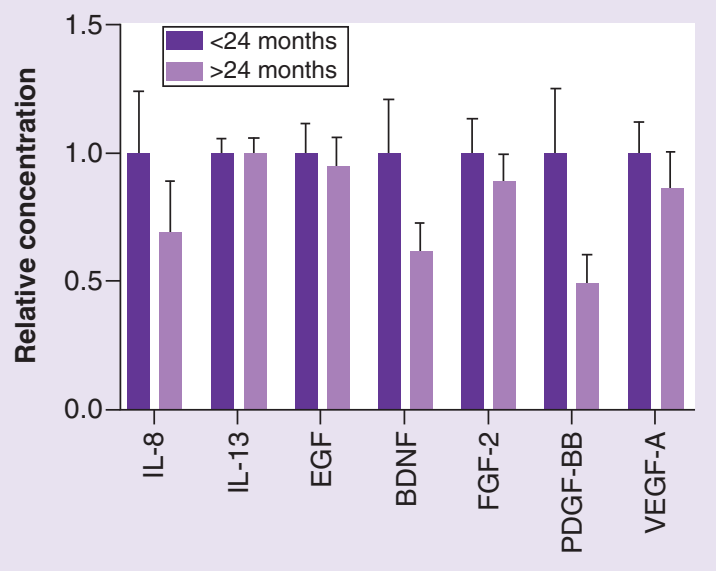

(C)

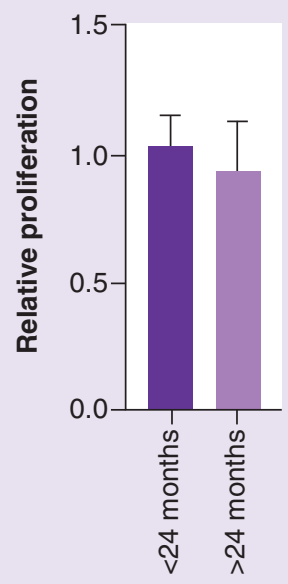

(D)

\begin{tabular}{|c|c|}
\hline No. of samples $>\mathbf{2 4}$ months & $\mathbf{4}$ \\
\hline Growth detected under following conditions \\
\hline Tryptic soy broth $\left(22.5^{\circ} \mathrm{C}\right)$ & $0 / 4$ \\
Sabdex broth $\left(22.5^{\circ} \mathrm{C}\right)$ & $0 / 4$ \\
Tryptic soy broth $\left(32.5^{\circ} \mathrm{C}\right)$ & $0 / 4$ \\
Fluid thioglycolate $\left(32.5^{\circ} \mathrm{C}\right)$ & $0 / 4$ \\
Tryptic soy agar plate $\left(22.5^{\circ} \mathrm{C}\right)$ & $0 / 4$ \\
Sabdex agar plate $\left(22.5^{\circ} \mathrm{C}\right)$ & $0 / 4$ \\
Tryptic soy agar plate $\left(32.5^{\circ} \mathrm{C}\right)$ & $0 / 4$ \\
\hline
\end{tabular}

(E)

\begin{tabular}{|c|c|c|c|c|c|}
\hline >24 months & Sample 1 & Sample 2 & Sample 3 & Sample 4 & Sample 5 \\
\hline Slope: & -0.402 & -0.402 & -0.402 & -0.371 & -0.371 \\
Intercept: & +2.319 & +2.319 & +2.319 & +2.402 & +2.402 \\
$\begin{array}{c}\text { Spike value } \\
\text { (recovered): }\end{array}$ & $0.833 \mathrm{EU} / \mathrm{ml}$ & $1.22 \mathrm{EU} / \mathrm{ml}$ & $0.863 \mathrm{EU} / \mathrm{ml}$ & $0.699 \mathrm{EU} / \mathrm{ml}$ & $0.632 \mathrm{EU} / \mathrm{ml}$ \\
$\begin{array}{c}\text { Spike reaction } \\
\text { time CV: }\end{array}$ & $13.6 \% \mathrm{pass}$ & $9.7 \% \mathrm{pass}$ & $21 \% \mathrm{pass}$ & $5.5 \% \mathrm{pass}$ & $3.4 \% \mathrm{pass}$ \\
$\begin{array}{c}\text { Spike recovery: } \\
\text { Sample value: }\end{array}$ & $98 \% \mathrm{pass}$ & $144 \% \mathrm{pass}$ & $102 \% \mathrm{pass}$ & $91 \% \mathrm{pass}$ & $82 \% \mathrm{pass}$ \\
SaUl & $<2.5 \mathrm{EU} / \mathrm{ml}$ & $<2.5 \mathrm{EU} / \mathrm{ml}$ & $<2.5 \mathrm{EU} / \mathrm{ml}$ & $<2.5 \mathrm{EU} / \mathrm{ml}$ & $<2.5 \mathrm{EU} / \mathrm{ml}$ \\
\hline
\end{tabular}

Figure 5. Determination of umbilical cord blood allograft stability. UCBr were divided into two groups based on their manufacturing date, less than 24 months $(\mathrm{N}=9-26)$ or greater $(\mathrm{N}=4-23)$. Cells were stained with AO/PI and counted with Nexcelom K2. Total and viable cell count (A) was determined. (B) MAGPIX protein multiplexing assay was performed to determine cytokine concentration in UCBr lysates grouped as in (A) with $\mathrm{N}=20$ donors in each group. Cytokine concentration of samples grouped as $>24$ months was expressed relative to the mean concentration of the $\mathrm{UCBr}$ samples grouped as $<24$ months. (C) Proliferation of $\mathrm{HC}$ treated with $\mathrm{UCBr}$ lysates was determined by CyQUANT assay. Data are normalized to samples grouped as $<24$ months and represented as mean of relative proliferation rate \pm standard deviation. (D) Data summarize growth-based microbiological testing to confirm aseptic nature for UCBr from four donors grouped as $>24$ months. (E) Endotoxin levels for UCBr from five donors grouped as $>24$ months was tested using EndoSafe-NexGen-PTS platform. Data were analyzed by Student's t-test and $p \leq 0.05$ was considered statistically significant. AO: Acridine orange; HC: Human knee articular chondrocytes; PI: Propidium iodide; UCBr: Umbilical cord blood allograft.

\section{Discussion}

As the clinical application of UCB allografts gains prominence, the mechanistic link between these products and tissue regeneration must be fully explored. Research on such allografts has mainly focused on the stem cell content due to their origin from birth tissues. However, studies in preclinical models make it evident that rather than stem cells, it is the trophic factors that have actual therapeutic impact in vivo [8]. We have previously shown that UCB-sourced allografts can induce proliferation, migration and angiogenesis by virtue of the cytokines present in UCB. The knowledge being gained from ongoing research on such allografts has prompted efforts to identify new quality control parameters that may be useful to define suitability release criteria. As the regulatory guidelines continue to evolve, parameters addressing regenerative mechanisms will also be likely included in the developing quality control framework. This is a first-of-its-kind study to put forth a set of quality control attributes which can be used to determine the clinical suitability of UCB-sourced allografts.

We enumerated the cellular component in addition to quantifying cytokines and identifying novel signaling proteins to have a complete picture of the allograft. The total cell count and percentage of cell viability was 
(A)

$1.74 \mathrm{E}+09$

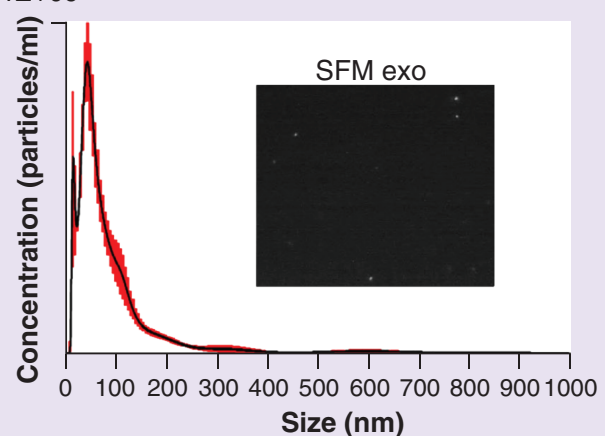

Size $(\mathrm{nm})$
(B)

3.31E+09

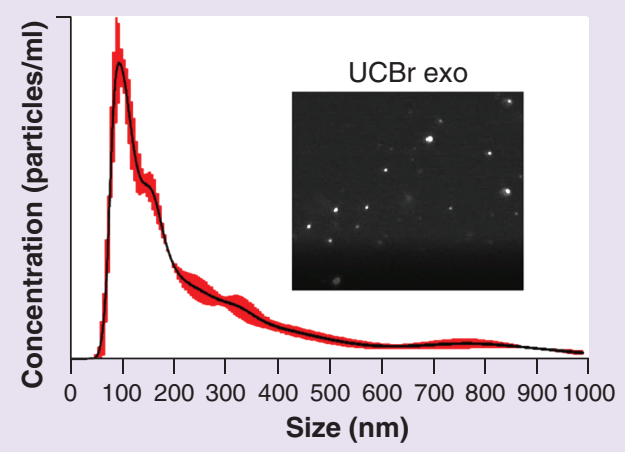

(D)

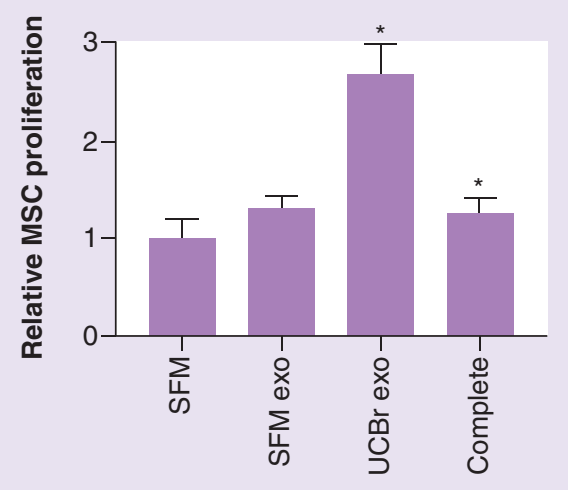

(E)

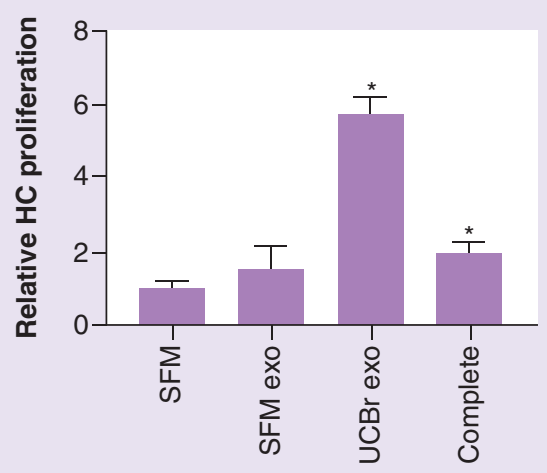

(c)

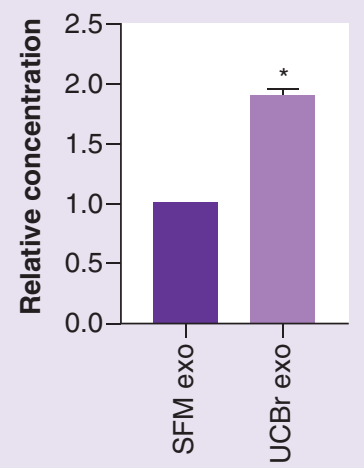

(F)

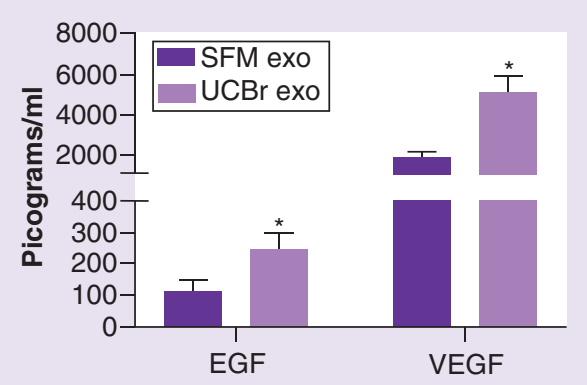

Figure 6. Effect of umbilical cord blood allograft on mesenchymal stem cell derived exosome. MSC were treated with SFM or UCBr lysate for $18 \mathrm{~h}$ and exosomes were collected from the respective conditioned media using protocol described in materials and method section. (A \& B) Quality/size distribution and representative screenshots of the isolated exosome as determined by fluorescence based nanoparticle tracking assay. (C) Relative yield of the microparticles by MSC treated with SFM or UCBr lysate is provided as mean \pm standard deviation. (D \& E) Proliferation of MSC (D) and HC (E) treated with either SFM, SFM-Exo, UCBr-Exo or complete media was measured by CyQUANT assay and values are expressed as mean fold change \pm standard deviation. (F) EGF and VEGF levels were measured using Luminex XMAP assay on MAGPIX ${ }^{\top M}$ platform in exosomes isolated from MSC treated with SFM or UCBr lysates.

Data were analyzed by Student's t-test or ANOVA and $p \leq 0.05$ was considered statistically significant.

${ }^{*} \mathrm{p} \leq 0.05$.

Exo/UCBr-Exo: Exosomes derived from MSC treated with SFM/UCBr; HC: Human knee articular chondrocyte; MSC: Mesenchymal stem cell; SFM: Serum free media; UCBr: Umbilical cord blood allograft.

consistent among the samples tested. Although cell viability and its metabolic activity cannot be correlated to the efficacy of the product, it is indicative of the uniformity of the manufacturing process. We identified a significant percentage of viable cells in $\mathrm{UCBr}$; however, a very low fraction stained positive for stem cell markers according to the International Society for Cellular Therapy guidelines [31]. These data do not preclude the possibility of stem cell presence in the cord blood sourced allograft cells. Isolation of stem cells from UCB has been successfully accomplished previously using specific tissue culture approaches [20,32]. It is interesting to see if UCBr cells cultured under such in vitro conditions over extended period of time enables better immunostaining of the stem cell surface markers. However, it is beyond the scope of this quality assessment study and may be a focus of future research. While we do not foresee dependence of $\mathrm{UCBr}$ on the viable cell population as a function of its clinical benefit, it demonstrates that the DMSO free cryopreservation techniques are gentle but effective to sustain these delicate cells. The two-way mixed lymphocyte reaction indicated that the cells present in $\mathrm{UCBr}$ do not proliferate, and the biological effects are independent of the metabolic function of these cells. Proteomic profiling of the samples revealed several proteins that can influence wound healing, ROS metabolism etc. To our knowledge, this is the first 
report identifying global proteins associated with UCB allografts. Random sampling for proteomic profiling as a part of routine quality control may identify possible deviation in the manufacturing process. About 31 cytokines that have a direct or indirect role in tissue regeneration were quantified from a large cohort of donors and found to be consistent. While donor variability is inevitable, strict inclusion-exclusion criteria based on quantitative identification of critical trophic factors can limit product variability and be a part of the quality control parameter.

cGTP guidelines were followed for determining the bioburden of the donated cord blood and the aseptic nature of UCBr. Less than $10 \%$ of the donated blood samples were rejected due to serology outcomes highlighting the importance of effective donor screening with well-defined donor inclusion-exclusion criteria. Processing in a constantly monitored, controlled environment can drastically reduce microbial contamination. In a span of 24 months, $99.98 \%$ processed products were aseptic. Allografts regulated as HCT/Ps are not required to be tested for endotoxin levels or immunogenicity. But based on the analysis of the reported use of these allografts, these tests may bear clinical relevance. Endotoxin levels of all $\mathrm{UCBr}$ products tested were $<2.5 \mathrm{EU} / \mathrm{ml}$ using the most stringent criteria of allowable endotoxin limit for pharmaceuticals. Testing endotoxin levels on each donor lot may be incorporated as a routine quality control measure to ensure clinical safety on certain instances. UCBr was nonimmunogenic as determined by MLR, on the contrary it suppressed the proliferation of the allogeneic PBMC. This can partially be attributed to the anti-inflammatory cytokines like IL-6, -10 and -13 . Concentration of another anti-inflammatory cytokine IL-1RA was approximately $30,000 \mathrm{pg} / \mathrm{ml}$, the highest among all the cytokines tested. Clinical trials on inhibition of IL-1 activity with IL-1RA have concluded that it is a safe and efficient way of alleviating GvHD that failed to respond to conventional treatment [33]. In future, it would be interesting to study the effects of $\mathrm{UCBr}$ in mitigating GvHD using preclinical models. Assessing the immunogenicity of the product at routine intervals indicates that the minimal processing requirement is effectively met such that the inherent nonimmunogenic property of the cord blood has not been compromised.

Apart from safety, another critical part of controlling product quality is determining consistency and lack of major variability from lot to lot. Reported use of UCB allografts in cartilage and soft tissue repair prompted us to perform experiments using articular chondrocytes as the model system. HC shows a continuous age-related decline in the proliferative response but can be activated by the mitogenic factors and chemokines like PDGF, SDF1 $\alpha$ and VEGF [34-36]. Cell free extracts of UCBr induced both proliferation and migration of chondrocytes by several folds. Results observed with a series of individual growth factors and cytokines identified PDGF as the most potent chemotactic factor for human articular chondrocytes [28]. Cytokine profiling of UCBr has confirmed presence of PDGF and several other factors. ROS generation is another age dependent factor leading to cartilage degradation [37,38]. Lack of defense toward the elevated levels of ROS generated from dysfunctional mitochondria has been shown to be mitigated by elevating the expression of antioxidant proteins [39,40]. Proteomic profiling of $\mathrm{UCBr}$ identified proteins that demonstrated involvement in ROS homeostasis. Therefore, we evaluated the effect of UCBr on expression of antioxidants. UCBr specifically upregulated MnSOD, Thioredoxin 1 and HMOX-1 but not Catalase, indicating that the antioxidant effect may be specific than indiscriminate. HMOX-1 is known to play a protective role against tissue injury in human cartilage by upregulating MnSOD, and is a therapeutic target in several pathological conditions related to elevated ROS generation [41]. Our data indicate potential involvement of several cytokines, enzymes and signaling molecules of $\mathrm{UCBr}$ in activating proliferation and migration of chondrocytes coupled with building antioxidant defense mechanisms to help in cartilage repair.

Long-term stability is another integral aspect of quality assessment. Volume reduced cord blood stored up to 15 years showed no alteration in post thaw quality [30,42,43]. However, there are no established guidelines to determine the maximum storage period for cryopreserved UCB sourced allografts. Initial storage conditions of $\mathrm{UCBr}$ at less than $-65^{\circ} \mathrm{C}$ was set for a period of 2 years. All post-thaw quality attributes were met by samples stored between 1 month and 25 months with no significant differences. Given these results, it can be concluded that $\mathrm{UCBr}$ is stable up to 2 years, but ongoing analysis as required by regulatory agencies will determine the actual expiration period.

With the advancement of our knowledge on secretome based therapy, we have started to appreciate the role of EVs/exosomes and consider it to be the next quantum leap in regenerative medicine [44-47]. While MSC derived exosomes are known to contain bioactive molecules that can alter the genetic and proteomic landscapes of the target cells, we were particularly interested to know if the yield and function of exosomes can be modulated by application of UCBr. This will be clinically relevant because host MSC activated by UCBr can release exosomes acting as 'enriched capsules' to trigger a more sustained regenerative outcome. Fluorescence-based nanoparticle tracking analysis identified intact EV-specific particle size and concentration. Current EV isolation methods may 
include protein aggregates, membrane fractions and other background particles, which have confounding effects. The structural integrity of the prepared EVs needs to be further characterized by cryo-electron microscopy. While most of these ideas are speculative, initial experiments indicate that exosomes derived from UCBr primed MSC have a higher cytokine content and proliferative effect, along with a higher yield. These data argue favorably for a potential liaison among $\mathrm{UCBr}$, host MSC and their derived exosomes to influence tissue regeneration in vivo. We are actively pursuing this line of research to elucidate the mechanistic role of EVs in tissue regeneration in greater detail.

\section{Conclusion}

As the field of regenerative medicine continues to evolve, the parameters required to establish its quality must be reviewed periodically and updated accordingly. Here, we put forward a set of experimental approaches to access the identity, safety, purity, potency, and stability of this UCB-based allograft.

\section{Translational perspective}

Procuring birth tissues to manufacturing allografts for regenerative therapy has been one of the most remarkable accomplishments in medical practice. However, leveraging the full benefit of these allografts depend on three major factors. First, there is a need to have a complete understanding of the molecular mechanism of action of the allograft; second, to exercise end-to-end control in the processing of the allograft from the birth tissues and at last to have adequate checks and balances in the quality control regime to maintain the highest standard of clinical safety. As the clinical demand of the allografts increases, the regulatory oversight on their manufacturing, marketing and clinical use is parallelly evolving to ascertain that patient safety and interest are not compromised. Considering these factors currently concerning the clinicians practicing regenerative medicine, we performed an array of experiments to develop a quality control regime suitable to clinically qualify a UCB allograft, based on its molecular/cellular component, purity, safety, efficacy and stability. Lessons from both translational research and ongoing clinical trials have led to a paradigm change in identifying the role of exogenous stem cells in tissue repair with concomitant appreciation of the effects of trophic factors in activating the endogenous host stem cells to execute the regenerative process. Therefore, when accounting for the clinical efficacy of UCB allografts, quality control measures should focus more on its ability to initiate signaling pathways to efficiently activate the host's MSC and other healing cells at the site of injury. In the future more clinical studies are required to explore the role of cytokines and growth factors associated with these allografts to fully harness their healing potential.

\section{Summary Points}

- Umbilical cord blood (UCB) sourced allografts are widely used in clinics for trauma and degenerative conditions. Since many products are registered as human cells, tissues, and cellular and tissue-based products, a defined regulatory framework is still evolving to address quality control attributes for such allografts.

- In this study, we identified tests to address critical quality attributes of UCB-allograft (UCBr) from a safety and potency perspective. In practice, identity, purity and safety tests can be adapted from existing guidelines, but potency assays/end points will vary based on reported application of the product.

- Here, we characterized the 'identity' of UCBr-cellular components, based on cell count, diameter and viability. Flow cytometric analysis of the mixed cell population using stem cell surface markers was used to effectively categorize cellular population in $\mathrm{UCBr}$. Mass spectrometry and protein multiplexing in decellularized $\mathrm{UCBr}$ quantified several different proteins, cytokines, growth factors and signaling molecules which constitutes the noncellular portion of this allograft. These tests may be routinely employed to monitor the product and assess the consistency of the manufacturing techniques.

- Endotoxin assay was used to determine 'purity' of the allograft. Aseptic clinical products derived from biological materials have an inherent risk of microbial contamination in the final product. Stringent donor inclusion-exclusion criteria were established based on peripheral blood serology and cord blood microbial testing. Additionally, cryopreserved final product underwent 'safety' testing based on growth-based microbiological cultures.

- Based on the reported application $\mathrm{UCBr}$ in cartilage repair and regeneration, biological efficacy of $\mathrm{UCBr}$ was tested in vitro using human chondrocytes.

- $\mathrm{UCBr}$ stored at temperature less than $-65^{\circ} \mathrm{C}$ was stable up to 24 months after production. Stability was established with protein multiplexing (stable chemical composition), endotoxin assay, potency assays (intact biological efficacy) and microbiological testing (maintaining aseptic nature).

- Identifying the tests that will characterize a biologics product is often challenging. To the best of our knowledge, this is the first report enumerating the tests to address identity, purity, safety and potency for a UCB allograft which may be developed into qualified and validated assays. 


\section{Supplementary data}

To view the supplementary data that accompany this paper please visit the journal website at: www.futuremedicine.com/doi/full/ 10.2217/rme-2019-0058

\section{Acknowledgments}

The authors acknowledge Dr B Onel (Xeno Diagnostics LLC) for her constructive inputs in FACS and MLR data analysis. M Kidd and the Regulatory Department at Burst Biologics helped in compiling the safety data. Excellent editorial assistance of D Thrasher is also acknowledged.

\section{Financial \& competing interests disclosure}

MS Sane, H Tang, S Banerjee Mustafi, CD Jones and S Malara are employees of Burst Biologics. N Misra was previously employed at Burst Biologics. Burst Biologics has filed a patent pertaining to the processing method of the UCB sourced allograft described in the manuscript. The authors have no other relevant affiliations or financial involvement with any organization or entity with a financial interest in or financial conflict with the subject matter or materials discussed in the manuscript apart from those disclosed.

No writing assistance was utilized in the production of this manuscript.

\section{Ethical conduct of research}

UCB was procured from consenting adults and manufactured in a US FDA-registered facility following all necessary regulatory guidelines as per the FDA's current Good Tissue Practice.

\section{References}

1. Miller RR, Roubenoff R. Emerging interventions for elderly patients - The promise of regenerative medicine. Clin. Pharmacol. Ther. 105(1), 53-60 (2019).

2. Lee MW, Jang IK, Yoo KH, Sung KW, Koo HH. Stem and progenitor cells in human umbilical cord blood. Int. J. Hematol. 92(1), 45-51 (2010).

3. Roura S, Pujal JM, Gálvez-Montón C, Bayes-Genis A. Quality and exploitation of umbilical cord blood for cell therapy: are we beyond our capabilities? Dev. Dynamics 245(7), 710-717 (2016).

4. Munoz J, Shah N, Rezvani K et al. Concise review: umbilical cord blood transplantation: past, present, and future. Stem Cells Transl. Med. 3(12), 1435-1443 (2014).

5. Rizk M, Aziz J, Shorr R, Allan DS. Cell-based therapy using umbilical cord blood for novel indications in regenerative therapy and immune modulation: an updated systematic scoping review of the literature. Biol. Blood Marrow Transplant.23(10), 1607-1613 (2017).

6. Park YB, Ha CW, Lee CH, Yoon YC, Park YG. Cartilage regeneration in osteoarthritic patients by a composite of allogeneic umbilical cord blood-derived mesenchymal stem cells and hyaluronate hydrogel: results from a clinical trial for safety and proof-of-concept with 7 years of extended follow-up. Stem Cells Transl. Med. 6(2), 613-621 (2017).

7. Roura S, Pujal J-M, Gálvez-Montón C, Bayes-Genis A. The role and potential of umbilical cord blood in an era of new therapies: a review. Stem Cell Res. Ther. 6(1), 123 (2015).

8. Baraniak PR, Mcdevitt TC. Stem cell paracrine actions and tissue regeneration. Regen. Med. 5(1), 121-143 (2010).

9. Sane MS, Misra N, Mousa OM et al. Cytokines in umbilical cord blood-derived cellular product: a mechanistic insight into bone repair. Regen. Med. 13(8), 881-898 (2018).

10. Caplan AI, Dennis JE. Mesenchymal stem cells as trophic mediators. J. Cell. Biochem. 98(5), 1076-1084 (2006).

11. Yáñez-Mó M, Siljander PR-M, Andreu Z et al. Biological properties of extracellular vesicles and their physiological functions. J. Extracell. Vesicles 4(1), 27066 (2015). doi: 10.3402/jev.v4.27066

12. Phelps J, Sanati-Nezhad A, Ungrin M, Duncan NA, Sen A. Bioprocessing of mesenchymal stem cells and their derivatives: toward cell-free therapeutics. Stem Cells Int. 2018, (2018). https://doi.org/10.1155/2018/9415367

13. Kishore R, Khan M. More than tiny sacks: stem cell exosomes as cell-free modality for cardiac repair. Circ. Res. 118(2), 330-343 (2016).

14. Phinney DG, Pittenger MF. Concise review: MSC-derived exosomes for cell-free therapy. Stem Cells 35(4), 851-858 (2017).

15. Rani S, Ryan AE, Griffin MD, Ritter T. Mesenchymal stem cell-derived extracellular vesicles: toward cell-free therapeutic applications. Mol. Ther. 23(5), 812-823 (2015).

16. U.S. Department of Health and Human Services, Food and Drug Administration, Center for Biologics Evaluation and Research. Guidance for human somatic cell therapy and gene therapy. Hum. Gene Ther.12(3), 303-314 (2001).

17. Lesche D, Geyer R, Lienhard D et al. Does centrifugation matter? Centrifugal force and spinning time alter the plasma metabolome. Metabolomics 12(10), 159 (2016). 
18. Pu X, Oxford JT. Proteomic analysis of engineered cartilage. In: Cartilage Tissue Engineering.Methods in Molecular Biology. Doran P. (Ed). Springer, Humana Press, NY, USA, 263-278, (2015).

19. Huang DW, Sherman BT, Lempicki RA. Systematic and integrative analysis of large gene lists using DAVID bioinformatics resources. Nat. Protoc. 4(1), 44 (2008).

20. Lee OK, Kuo TK, Chen W-M, Lee K-D, Hsieh S-L, Chen T-H. Isolation of multipotent mesenchymal stem cells from umbilical cord blood. Blood 103(5), 1669-1675 (2004).

21. Secunda R, Vennila R, Mohanashankar A, Rajasundari M, Jeswanth S, Surendran R. Isolation, expansion and characterisation of mesenchymal stem cells from human bone marrow, adipose tissue, umbilical cord blood and matrix: a comparative study. Cytotechnology 67(5), 793-807 (2015).

22. Zhang $\mathrm{X}$, Hirai $\mathrm{M}$, Cantero $\mathrm{S}$ et al. Isolation and characterization of mesenchymal stem cells from human umbilical cord blood: reevaluation of critical factors for successful isolation and high ability to proliferate and differentiate to chondrocytes as compared with mesenchymal stem cells from bone marrow and adipose tissue. J. Cell. Biochem. 112(4), 1206-1218 (2011).

23. Andrade PZ, Da Silva CUL, Dos Santos F, Almeida-Porada G, Cabral JM. Initial CD34+ cell-enrichment of cord blood determines hematopoietic stem/progenitor cell yield upon ex vivo expansion. J. Cell. Biochem. 112(7), 1822-1831 (2011).

24. Ährlund-Richter L, De Luca M, Marshak DR, Munsie M, Veiga A, Rao M. Isolation and production of cells suitable for human therapy: challenges ahead. Cell Stem Cell 4(1), 20-26 (2009).

25. Dinarello CA, Simon A, Van Der Meer JW. Treating inflammation by blocking interleukin-1 in a broad spectrum of diseases. Nat. Rev. Drug Dis. 11(8), 633 (2012).

26. Cho PS, Messina DJ, Hirsh EL et al. Immunogenicity of umbilical cord tissue-derived cells. Blood 111(1), 430-438 (2008).

27. Charalambous CP. Articular cartilage. Part II: degeneration and osteoarthrosis, repair, regeneration, and transplantation. In: Classic Papers in Orthopaedics, Banaszkiewicz P, Kader D. (Eds). Springer, London, UK, 389-391 (2014).

28. Mishima Y, Lotz M. Chemotaxis of human articular chondrocytes and mesenchymal stem cells. J. Orthop. Res. 26(10), 1407-1412 (2008).

29. Henrotin Y, Bruckner P, Pujol J-P. The role of reactive oxygen species in homeostasis and degradation of cartilage. Osteoarthritis Cartilage 11(10), 747-755 (2003).

30. Yamamoto S, Ikeda H, Toyama D et al. Quality of long-term cryopreserved umbilical cord blood units for hematopoietic cell transplantation. Int. J. Hematol. 93(1), 99-105 (2011).

31. Dominici M, Le Blanc K, Mueller I et al. Minimal criteria for defining multipotent mesenchymal stromal cells. The International Society for Cellular Therapy position statement. Cytotherapy 8(4), 315-317 (2006).

32. Sibov TT, Severino P, Marti L et al. Mesenchymal stem cells from umbilical cord blood: parameters for isolation, characterization and adipogenic differentiation. Cytotechnology 64(5), 511-521 (2012).

33. Park M-J, Lee SH, Lee S-H et al. IL-1 receptor blockade alleviates graft-versus-host disease through downregulation of an interleukin-1-dependent glycolytic pathway in Th17 cells. Mediators Inflamm. 2015, doi: 10.1155/2015/631384, (2015).

34. Schmidt M, Chen E, Lynch S. A review of the effects of insulin-like growth factor and platelet derived growth factor on in vivo cartilage healing and repair. Osteoarthritis Cartilage 14(5), 403-412 (2006).

35. Gaissmaier C, Koh JL, Weise K. Growth and differentiation factors for cartilage healing and repair. Injury 39(1), 88-96 (2008).

36. Wang Y, Sun X, Lv J, Zeng L, Wei X, Wei L. Stromal cell-derived factor-1 accelerates cartilage defect repairing by recruiting bone marrow mesenchymal stem cells and promoting chondrogenic differentiation. Tissue Eng. Part A 23(19-20), 1160-1168 (2017).

37. Hui W, Young DA, Rowan AD, Xu X, Cawston TE, Proctor CJ. Oxidative changes and signalling pathways are pivotal in initiating age-related changes in articular cartilage. Ann. Rheum. Dis. 75(2), 449-458 (2016).

38. Li Y, Wei X, Zhou J, Wei L. The age-related changes in cartilage and osteoarthritis. BioMed Res. Int. 2013, doi: 10.1155/2013/916530 (2013).

39. Lomri A. Role of reactive oxygen species and superoxide dismutase in cartilage aging and pathology. Int. J. Clin. Rheum. 3(4), 381 (2008).

40. Ruiz-Romero C, Calamia V, Mateos J et al. Mitochondrial dysregulation of osteoarthritic human articular chondrocytes analyzed by proteomics: a decrease in mitochondrial superoxide dismutase points to a redox imbalance. Mol. Cell. Proteom. 8(1), 172-189 (2009).

41. Li X, Wang H, Touma E, Rousseau E, Quigg RJ, Ryaby JT. Genetic network and pathway analysis of differentially expressed proteins during critical cellular events in fracture repair. J. Cell. Biochem. 100(2), 527-543 (2007).

42. Mugishima H, Harada K, Chin M et al. Effects of long-term cryopreservation on hematopoietic progenitor cells in umbilical cord blood. Bone Marrow Transplant. 23(4), 395 (1999).

43. Broxmeyer HE, Srour EF, Hangoc G, Cooper S, Anderson SA, Bodine DM. High-efficiency recovery of functional hematopoietic progenitor and stem cells from human cord blood cryopreserved for 15 years. Proc. Natl Acad. Sci. USA 100(2), 645-650 (2003).

44. Keshtkar S, Azarpira N, Ghahremani MH. Mesenchymal stem cell-derived extracellular vesicles: novel frontiers in regenerative medicine. Stem Cell Res. Ther. 9(1), 63 (2018). 
45. De Jong OG, Van Balkom BW, Schiffelers RM, Bouten CV, Verhaar MC. Extracellular vesicles: potential roles in regenerative medicine. Front. Immunol. 5, 608 (2014).

46. Monguió-Tortajada M, Roura S, Gálvez-Montón C, Pujal JM, Aran G, Sanjurjo L. Nanosized UCMSC-derived extracellular vesicles but not conditioned medium exclusively inhibit the inflammatory response of stimulated $\mathrm{T}$ cells: implications for nanomedicine. Theranostics 7(2), 270 (2017).

47. Roura S, Vives J. Extracellular vesicles: squeezing every drop of regenerative potential of umbilical cord blood. Metabolism 95, 102-104 (2019). 